ORNL/TM-6862

D1st. Category UC-79, $-79 e,-79 p$

Contract No. W-7405-eng-26

Engineering Technology Division

\title{
A COMPARISON OF COMPUTATIONAL RESULTS OF THE SABRE LMFBR PIN BUNDLE BLOCKAGE CODE WITH DATA FROM WELL-INSTRUMENTED OUT-OF-PILE TEST BUNDLES (THORS BUNDLES 3A AND 5A)
}

\section{J. F. Dearing}

This report was prepared as an account of work
sponsored by the United States Govemment. Neither the
United States nor the United States Department of
Energy, nor any of theis employees, nor any of their
con tractors, subcontractors, or their employees, makes
any warranty, express or implied, or assumes any legal
liability or responsibility for the accuracy, completeness
or usefulness of any information, apparatus, product or
process disclosed, or reptesents that its use would not
infringe privately owned rights.

Date Published - September 1979

NOTICE: This document contains information of a preliminary nature. It is subject to revision or correction and therefore does not represent a final report.

This document is PUBLICLY RELEASABLE David R. Hamrin, ORNL Authorizing Official

Date $5-8-2008$
Prepared by the OAK RIDGE NATIONAL LABORATORY Oak Ridge, Tennessee 37830 operated by UNION CARBIDE CORPORATION for the DEPARTMENT OF ENERGY
Releasea for Announceinent in Energy

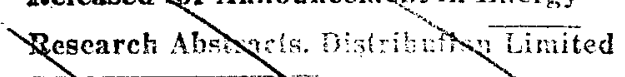

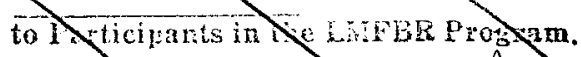
Others hequest from ixc 


\section{DISCLAIMER}

This report was prepared as an account of work sponsored by an agency of the United States Government. Neither the United States Government nor any agency Thereof, nor any of their employees, makes any warranty, express or implied, or assumes any legal liability or responsibility for the accuracy, completeness, or usefulness of any information, apparatus, product, or process disclosed, or represents that its use would not infringe privately owned rights. Reference herein to any specific commercial product, process, or service by trade name, trademark, manufacturer, or otherwise does not necessarily constitute or imply its endorsement, recommendation, or favoring by the United States Government or any agency thereof. The views and opinions of authors expressed herein do not necessarily state or reflect those of the United States Government or any agency thereof. 


\section{DISCLAIMER}

Portions of this document may be illegible in electronic image products. Images are produced from the best available original document. 


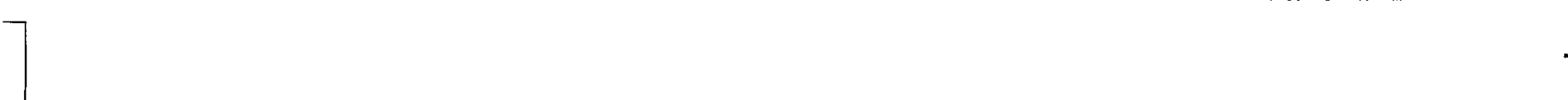




\section{CONTENTS}

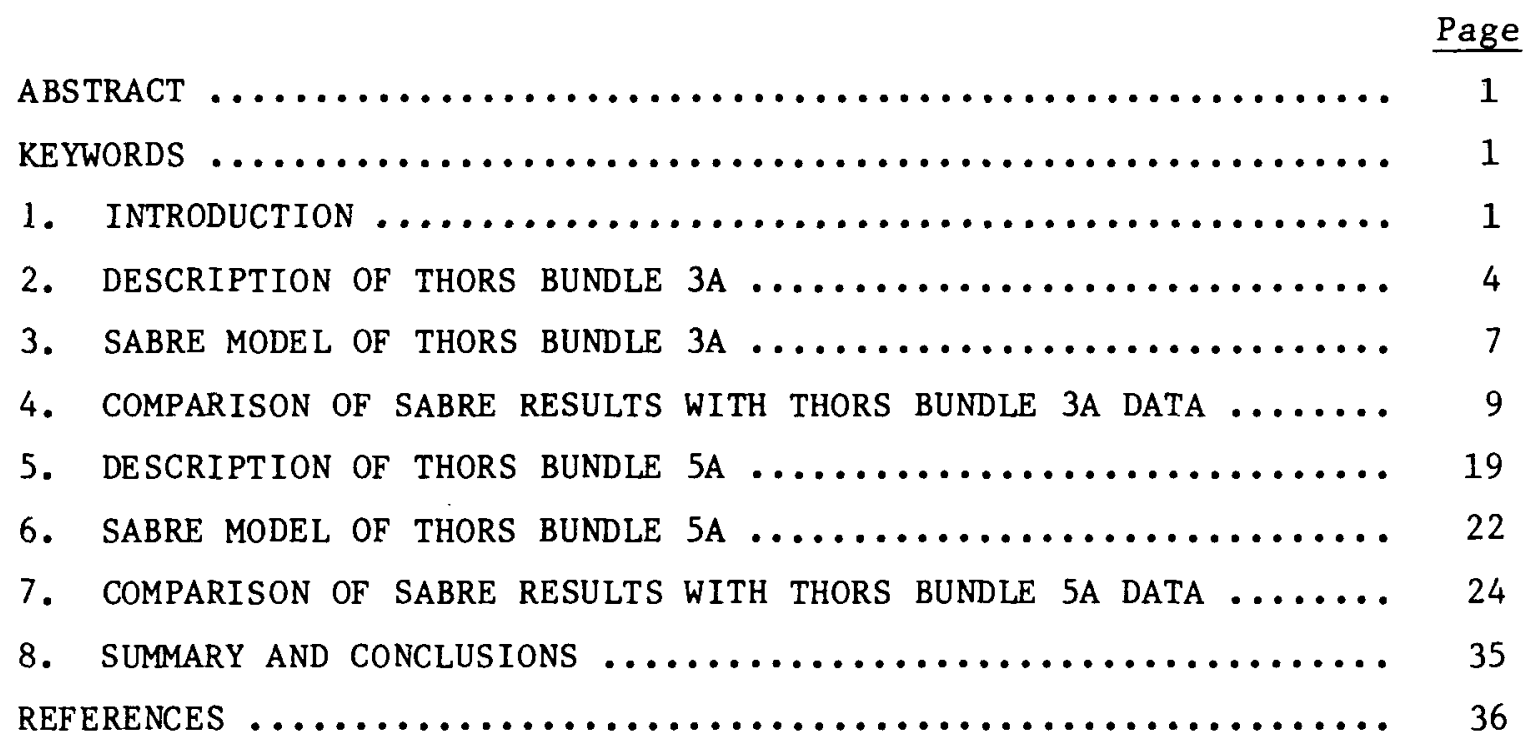


A COMPARISON OF COMPUTATIONAL RESULTS OF THE SABRE LMFBR PIN BUNDLE BLOCKAGE CODE WITH DATA FROM WELL-INSTRUMENTED

OUT - OF-PILE TEST BUNDLES (THORS BUNDLES 3A AND 5A)

J. F. Dearing

ABSTRACT

The Subchannel Analysis of Blockages in Reactor Elements (SABRE) computer code, developed by the United Kingdom Atomic Energy Authority, is currently the only practical tool available for performing detailed analyses of velocity and temperature fields in the recirculating flow regions downstream of blockages in liquid-metal fast breeder reactor (LMFBR) pin bundles. SABRE is a subchannel analysis code; that is, it accurately represents the complex geometry of nuclear fuel pins arranged on a triangular lattice. The results of SABRE computational models are compared here with temperature data from two out-of-pile 19-pin test bundles from the Thermal-Hydraulic Out-of-Reactor Safety (THORS) Facility at Oak Ridge National Laboratory. One of these bundles has a small central flow blockage (bundle $3 \mathrm{~A}$ ), while the other has a large edge blockage (bundle 5A). Values that give best agreement with experiment for the empirical thermal mixing correlation factor, "FMIX," in SABRE are suggested. These values of FMIX are Reynolds-number dependent, however, indicating that the coded turbulent mixing correlation is not appropriate for wire-wrap pin bundles.

Keywords: sodium, LMFBR, computer code, subchannel analysis, flow blockage, out-of-pile experiment.

\section{INTRODUCTION}

The core of a Liquid-Metal Fast Breeder Reactor (LMFBR) is a region of extremely high power density which is cooled effectively by sodium flowing between the fuel pins under normal operating conditions. Maintenance of design-temperature limitations of the fuel and cladding is critically dependent on the small sodium flow channels between the tightly packed fuel pins remaining open. The possibility (although it now appears remote) that the blockage of only a few flow channels could lead to a whole core-disruptive accident led to extensive out-of-pile 
flow blockage testing at the Therma1-Hydraulic Out-of-Reactor Safety (THORS) Facility at Oak Ridge National Laboratory* (ORNL). These tests were run with two planar blockage configurations - a small central blockage (bundle $3 \mathrm{~A}$ ) and a large edge blockage (bundle 5A). Both bundles $3 \mathrm{~A}$ and $5 \mathrm{~A}$ were 19-pin electrically heated, wire-wrap bundles that were designed to simulate core thermal-hydraulic behavior of the Fast Flux Test Facility (FFTF) and Clinch River Breeder Reactor (CRBR).

Computational simulation of flow and temperature structure in the complex geometry of a blocked pin bundle is very difficult, and, until recently, most analytical work involved simple residence time models. The Subchannel Analysis of Blockages in Reactor Elements ${ }^{1-3}$ (SABRE) computer code, developed by the United Kingdom Atomic Energy Authority (UKAEA), is the first attempt to solve the three-dimensional coupled mass, momentum, and energy conservation equations in blocked pin bundle geometry. Although development of the code is continuing and many empirical correlations have yet to be precisely determined, comparing the code as developed to date with experimental data is worthwhile. Comparisons such as this should refine the computational model and indicate possible future development.

The first half of this report (Sects. 2, 3, and 4) deals with the small central blockage of THORS bundle $3 \mathrm{~A}$. This is not a very difficult test for SABRE because the actual recirculation zone is very small, encompassing less than one subchannel (i.e., every blocked subchannel is adjacent to an unblocked one). Because SABRE deals in subchannel average velocities, it does not even "see" a recirculation zone. The SABRE code, however, does predict accurately the rate of flow recovery behind the blockage because agreement with experimental data in this region is excellent.

The second half of this report (Sects. 5, 6, and 7) deals with the large edge blockage of THORS bundle 5A. This blockage produces a recirculation zone $\sim 40$ to $60 \mathrm{~mm}$ long (for inlet flow 10 to $100 \%$ nominal). SABRE-computed temperatures can be made to fit THORS data by adjusting the turbulent thermal mixing parameter, "FMIX," but the fit is dependent on inlet velocity. A wire-wrap diversion crossflow model and a mixing 
correlation for wire-wrap bundles will be necessary if SABRE is to be used extensively as a tool in wire-wrap bundle blockage analysis.

The versions of SABRE used here are SABRE-1 (Amendment 2 ) $^{2}$ and SABRE-1A. 3 SABRE-1A was developed to eliminate the "false" or numerical diffusion error introduced by the upwind finite differencing scheme in SABRE-1. Details of the solution procedure in SABRE are considered "Commercial in Confidence," so they will not be discussed. Although a version of SABRE containing provisions for wire-wrap forced-diversion crossflow has recently been made available, it was not used here because it does not contain the vector upwind differencing algorithm (for eliminating false diffusion) of SABRE-1A, nor is it applicable to recirculating flow. Nondirectional thermal mixing effects of wire wraps are accounted for (by adjustment of the empirical factor FMIX) in this report, but directional effects are not. 


\section{DESCRIPTION OF THORS BUNDLE 3A}

The THORS Facility at ORNL is a large, high-temperature sodium loop in which pin bundles simulating LMFBR core segments are tested. Those tests include both normal and off-normal conditions. The flow blockage is an important off-normal condition, and THORS bundle $3 \mathrm{~A}$ was designed to investigate the effects of a small, six-channel central blockage.

Bundle $3 \mathrm{~A}$ consisted of 19 electric cartridge heaters with outside diameters of $5.8 \mathrm{~mm}$ ( $0.23 \mathrm{in.)}$ that were spaced by $1.4-\mathrm{mm}-\mathrm{diam}(0.56-\mathrm{in}$. wire-wrap spacers on a 305-mm (12-in.) pitch. A 6.4-mm-thick (0.25-in.) stainless steel plate blocked flow in the six central subchannels (Fig. 1) at $381 \mathrm{~mm}$. (15 in.) downstream from the beginning of the 533-mm-long (21-in.) heated section. The interior of a large subassembly was simulated using a scalloped duct wall, as shown in Fig. 1.

Figure 2 shows the location of thermocouple instrumentation used in this report. Included are wire-wrap, heater-internal, and exit-rake thermocouples. Because of the difficulty in comparing computed subchannel average sodium temperatures with heater-internal thermocouple data, only wire-wrap and exit-rake data are used here. The difference between

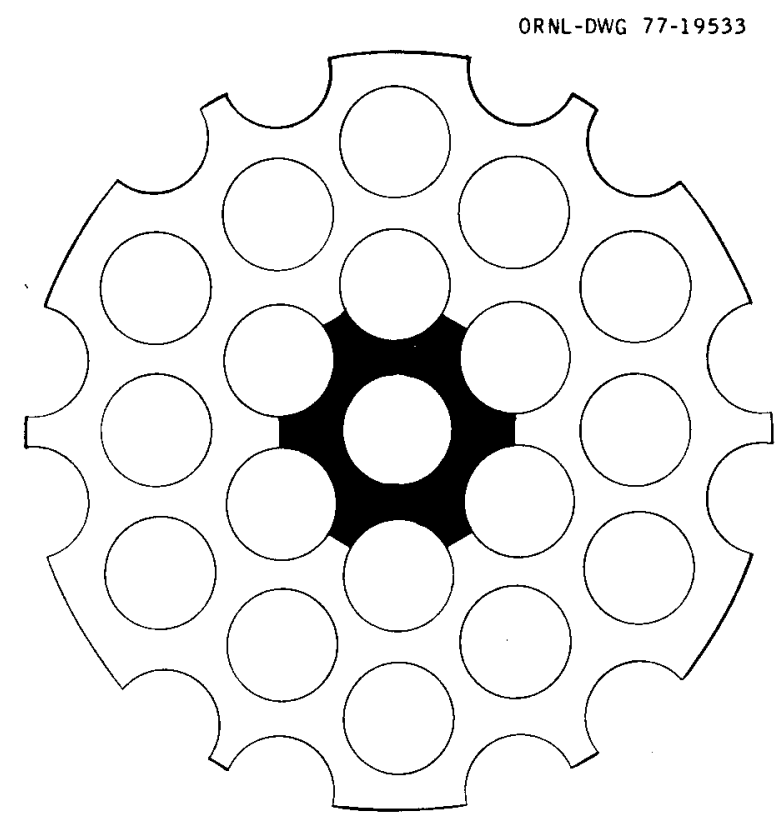

Fig. 1. Cross section of THORS bundle $3 \mathrm{~A}$ showing six-channel central blockage. 


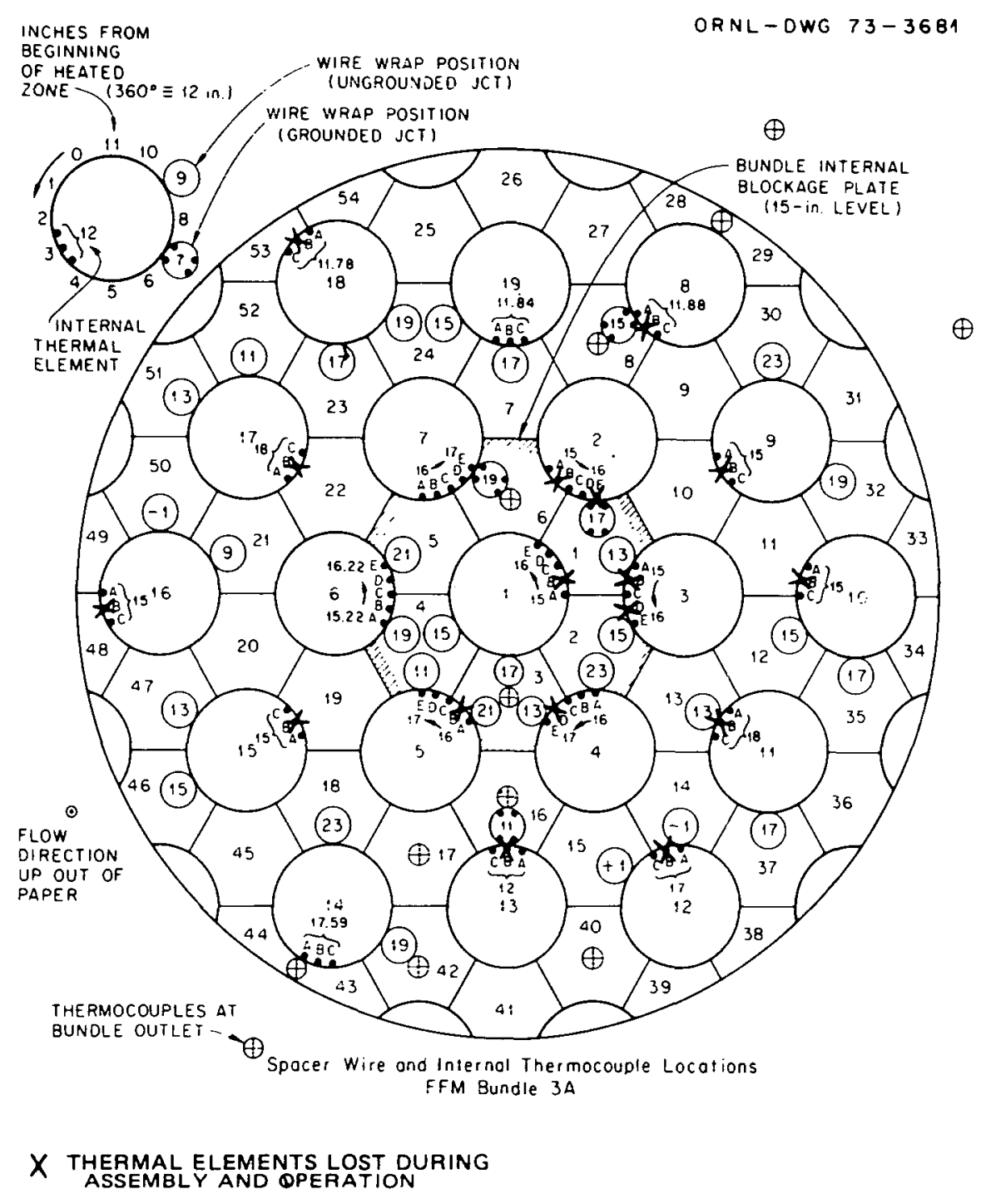

Fig. 2. Cross section of THORS bundle $3 \mathrm{~A}$ showing outline of blockage and locations of thermocouples ( $1 \mathrm{in}$. $=25.4 \mathrm{~mm}$ ).

the temperature measured by a wire-wrap thermocouple and the average sodium temperature of the subchannel in which the thermocouple is located is probably small $\left(\left\langle 5^{\circ} \mathrm{C}\right)\right.$. The exit rake is downstream of the heated section, so there should be no difference between exit-rake thermocouple and subchannel average temperatures.

Figure 3 shows the bundle $3 A$-test section. Sodium enters near the bottom, flows up through the bundle, and exits near the top. A complete description of bundle $3 \mathrm{~A}$, along with all experimental data, may be found in Ref. 4. 


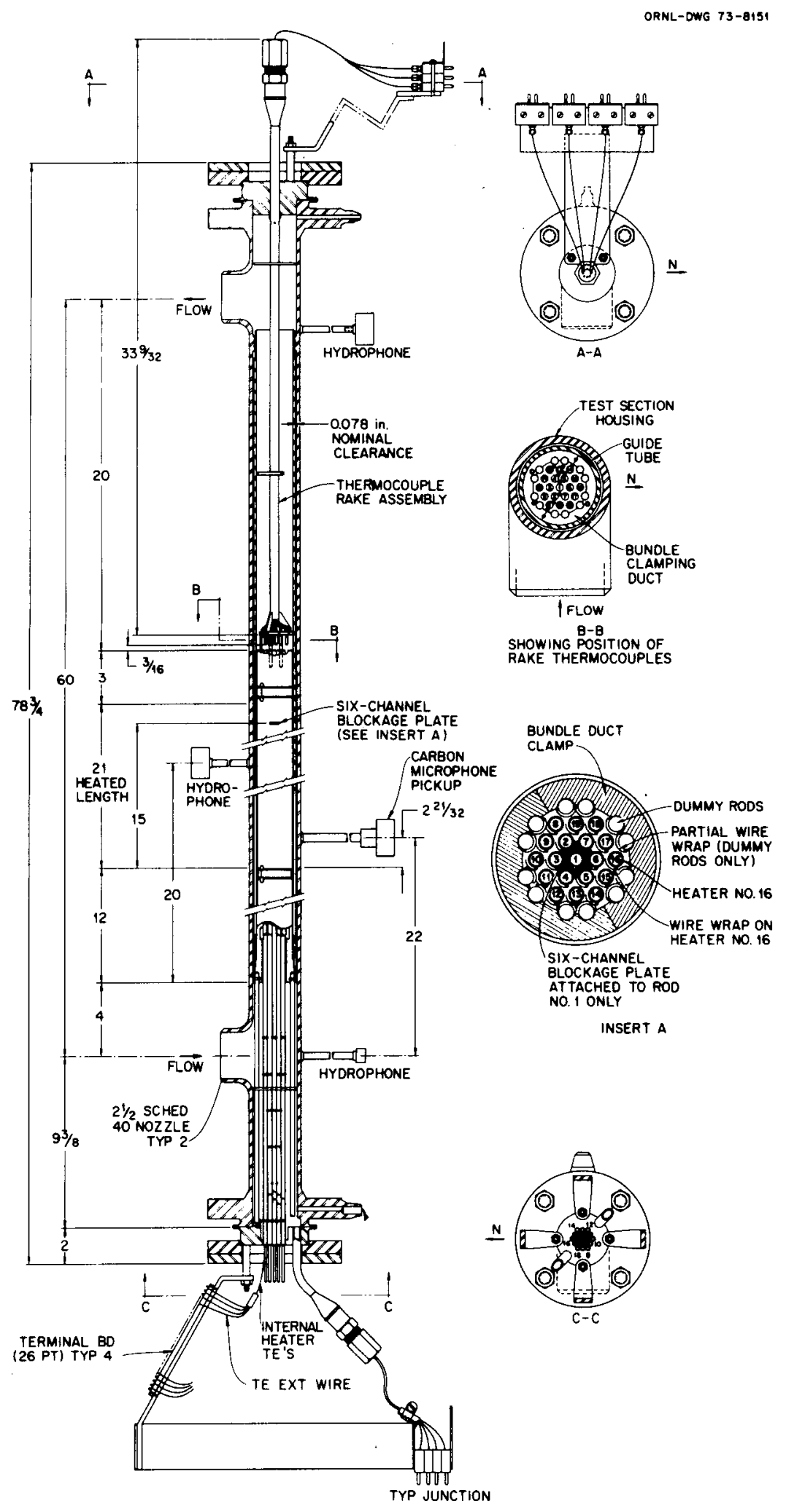

Fig. 3. THORS bundle 3 A test $\operatorname{section}(1 \mathrm{in} .=25.4 \mathrm{~mm}$ ). 


\section{SABRE MODEL OF THORS BUNDLE 3A}

A one-sixth section model of bundle $3 \mathrm{~A}$ is shown in Fig. 4. Subchannel types are identified as "B," "1C," "1E," etc. The model extends from the beginning of the heated section to the end of the bundle, a distance of $610 \mathrm{~mm}(24 \mathrm{in.})$. The heated section is $533 \mathrm{~mm}$ (21 in.) long, ending $76 \mathrm{~mm}$ ( $3 \mathrm{in.}$ ) before the end of the bundle, where the exit-rake thermocouples are located. Axial nodes are a uniform $6.35 \mathrm{~mm}$ (0.25 in.) long, except for the first node and the node containing the end of the heated section, which are $9.53 \mathrm{~mm}(0.375 \mathrm{in.})$ long. These two nonuniform nodes are necessary to locate the blockage plate properly in the axial nodalization. This SABRE model required $\sim 430 \mathrm{~K}$ bytes of storage and $\sim 5$ min of running time on an IBM $360 / 91$.

ORNL-DWG 77-11235A

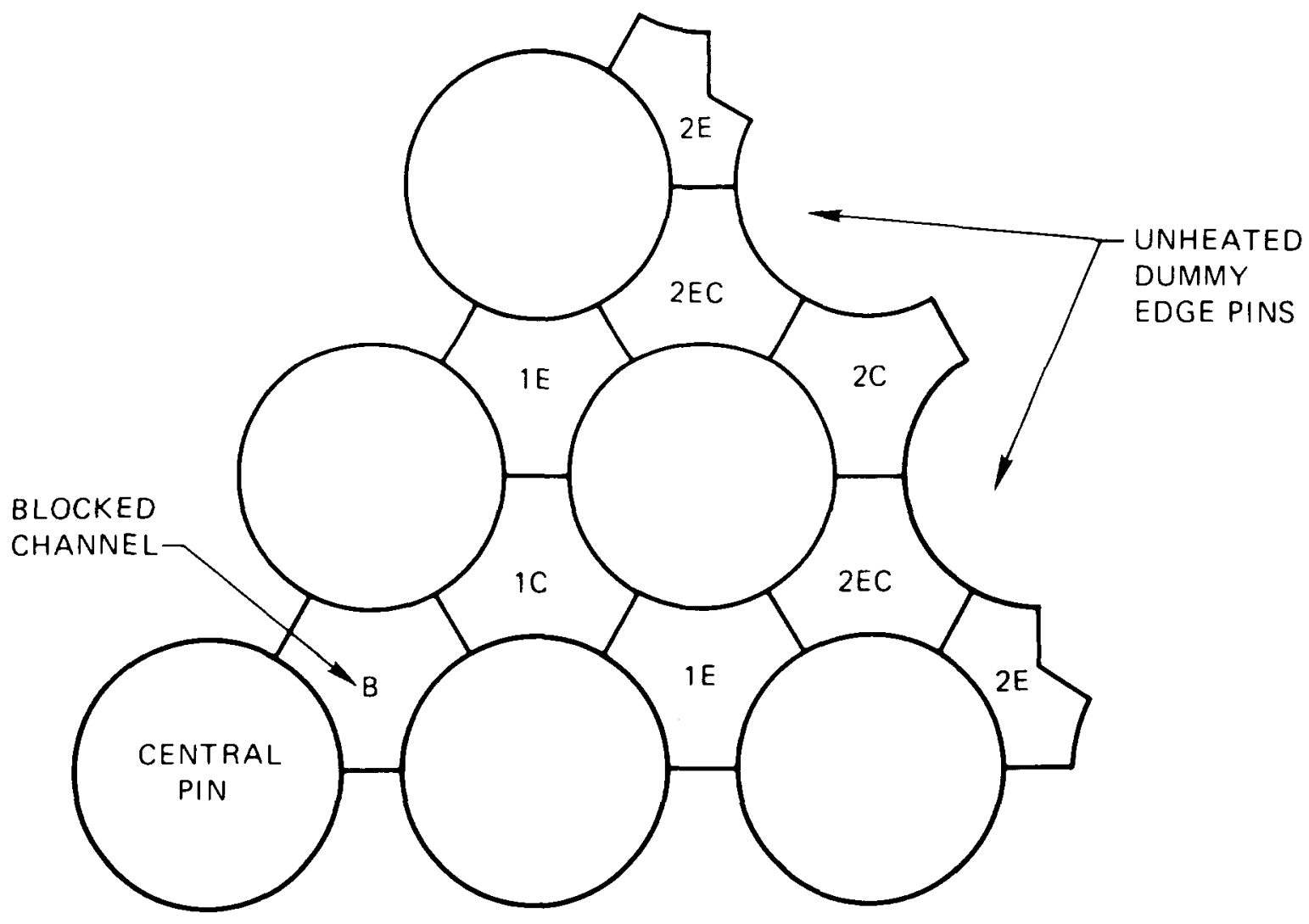

Fig. 4. SABRE model of THORS bundle 3A - one-sixth section. 
A one-sixth section model was possible because the blockage is symmetrical about a one-sixth section and because SABRE does not include provisions for wire-wrap forced-diversion crossflow (which would destroy the symmetry). Bundle $3 \mathrm{~A}$ does have wire wraps, however, so it is not exactly symmetrical. The effect of this discrepancy will be seen in the next chapter as a scatter of data representing the same channel type (in one-sixth section) but in different sections of the bundle. The scatter will be seen to be least significant in the important central blocked channels.

SABRE has the option of inlet velocity (meters per second) or pressure drop (Pascals) boundary condition. The pressure drop boundary condition is the more desirable, but there are no experimental data for pressure drop across the axial region modeled. If a pressure drop boundary condition is to be used, the correct inlet flow (which is measured experimentally) must be achieved by iteration. This was done for several cases on both bundle $3 \mathrm{~A}$ and $5 \mathrm{~A}$ models. There were no significant differences in the solutions obtained using the two types of boundary conditions, so the inlet velocity boundary condition is used throughout this analysis.

The subchannel flow areas and wetted perimeters used in SABRE are modified to account for the presence of the wire wraps. These are average modifications, that is, the flow area and wetted perimeter of a particular subchannel do not change with axial position (as wire wraps sweep in and out).

Default values of all correlation parameters are used throughout, except for the turbulent thermal mixing correlation parameter FMIX and "GAMBL," the thermal conductivity divided by the specific heat of the blockage material. FMIX is varied to give best agreement with experimental data, while GAMBL was assigned a value of $0.02 \mathrm{~kg} \mathrm{sec}^{-1} \mathrm{~m}^{-1}$ (for stainless steel). However, the effect of GAMBL is only significant to the SABRE-computed temperatures at nodes within the blockage, and these temperatures are ignored in this analysis (the SABRE representation of in-blockage heat transfer is too simplified to be of value). Convergence was fastest using a value of 0.3 to 0.4 for the velocity underrelaxation factor, "URFVEL." 


\section{COMPARISON OF SABRE RESULTS WITH THORS BUNDLE 3A DATA}

SABRE results and THORS data are compared for three runs, representing $\sim 100,80$, and $60 \%$ nominal flow. Table 1 gives experimental conditlons for these three cases: runs 101, 104, and 107 of test 2, series 4 of the bundle $3 \mathrm{~A}$ test program (Ref. 4).

Table 1. Experimental conditions for three runs of test 2 , series 4 , bundle $3 A$ test program

\begin{tabular}{lccccc}
\hline $\begin{array}{c}\text { Run } \\
\text { No. }\end{array}$ & $\begin{array}{c}\text { Approximate } \\
\text { nominal } \\
\text { flow } \\
(\%)\end{array}$ & $\begin{array}{c}\text { Inlet flow } \\
(\text { liters sec }\end{array}$ & $\begin{array}{c}\text { Power/pin } \\
(\mathrm{kW})\end{array}$ & $\begin{array}{c}\text { Inlet } \\
\text { temperature } \\
\left({ }^{\circ} \mathrm{C}\right)\end{array}$ & $\begin{array}{c}\text { Bulk } \\
\text { temperature } \\
\text { rise, } \\
\left({ }^{\circ} \mathrm{C}\right)\end{array}$ \\
\hline 101 & 100 & 3.39 & 17.52 & 441 & 90 \\
104 & 80 & 2.72 & 17.55 & 434 & 110 \\
107 & 60 & 2.10 & 17.54 & 418 & 142 \\
\hline
\end{tabular}

Figure 5 shows SABRE-computed relative subchannel axial velocities (velocity/inlet velocity) in subchannel types $B, 1 C$, and $1 E$ as functions of axial distance from the front face of the blockage plate for $100 \%$ of nominal flow. Note that the axial velocity in B (the blocked subchannel) falls rapidly to zero upstream of the blockage and recovers slowly downstream. The velocity is positive everywhere - SABRE does not "see" a recirculation zone because it is too small to be defined on a subchannel average basis.

SABRE temperatures and THORS wire-wrap and exit-rake thermocouple data are compared using plots of normalized temperature vs axial position in the bundle. Normalized temperature is defined

$$
T_{n}=\left(T-T_{i n}\right) / T_{B},
$$

where $\mathrm{T}$ is the indicated temperature $\left({ }^{\circ} \mathrm{C}\right), \mathrm{T}_{1 \mathrm{n}}$ is the bundle inlet temperature $\left({ }^{\circ} \mathrm{C}\right)$, and $\mathrm{T}_{\mathrm{B}}$ is the bulk temperature rise through the heated section $\left({ }^{\circ} \mathrm{C}\right)$. 


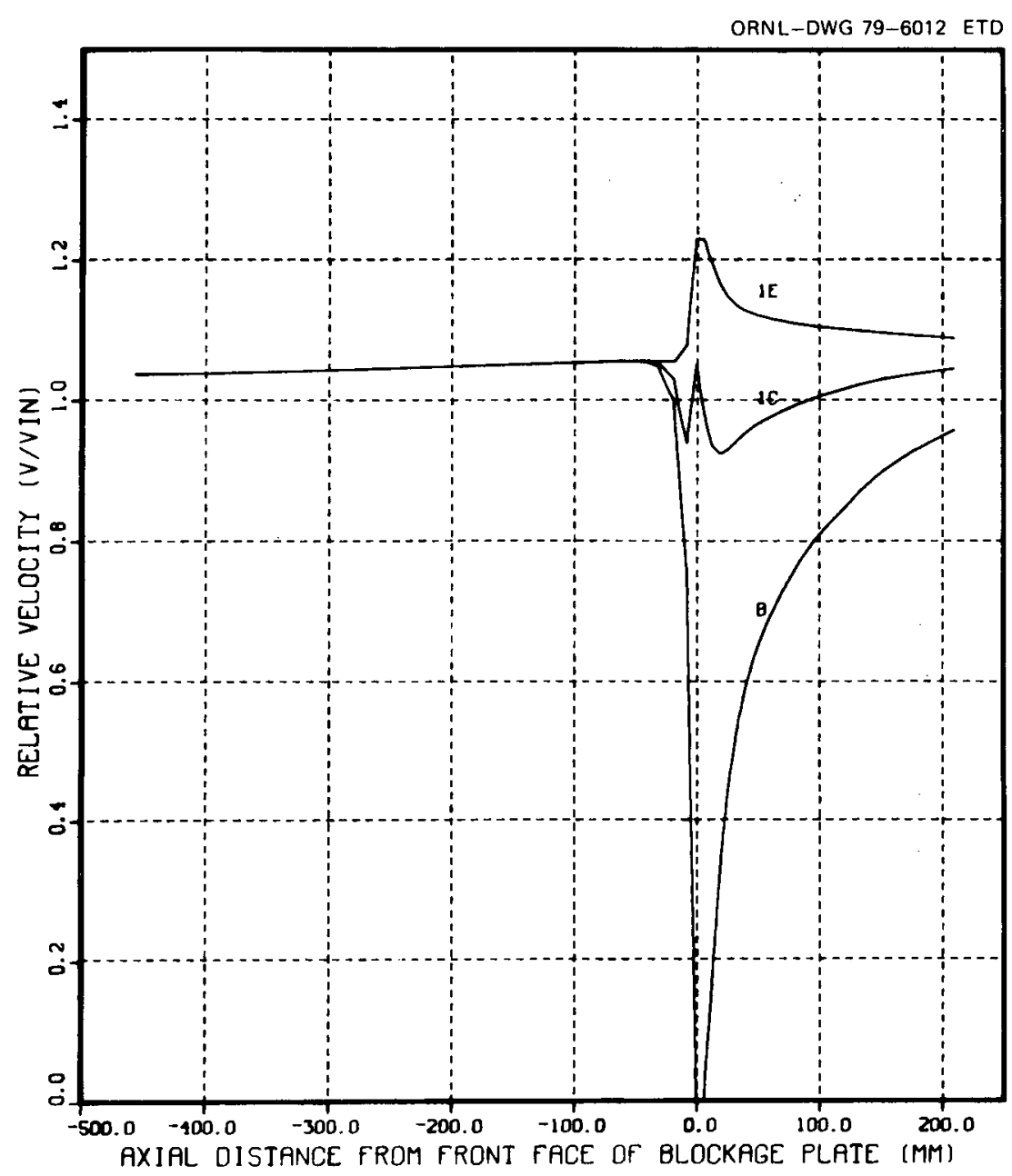

Fig. 5. SABRE-1 computed relative axial velocities for subchannel types $B, 1 C$, and $1 E$ for conditions of test 2, run 101 .

Values used for $T_{1}$ and $T_{B}$ for each run may be found in Table 1. Figures 6,7 , and 8 show normalized temperature vs axial position for subchannel types $B, 1 E$, and $2 E C$, respectively, for run $101(100 \%$ nominal flow). SABRE-1 (Amendment 2), with the default value of FMIX = 1.0 , was used. The agreement with experiment is very good, especially for the blocked central subchannel B. Scatter of data at the same axial location is caused by wire-wrap mixing and is more prevalent at the edge of the bundle (2EC) than in the center (B). These plots are included to show that SABRE-1 (Amendment 2) does a very adequate job of modeling this small blockage case. Apparently, false diffusion is not a problem here. The remainder of the analysis in this report will use SABRE-1A. 


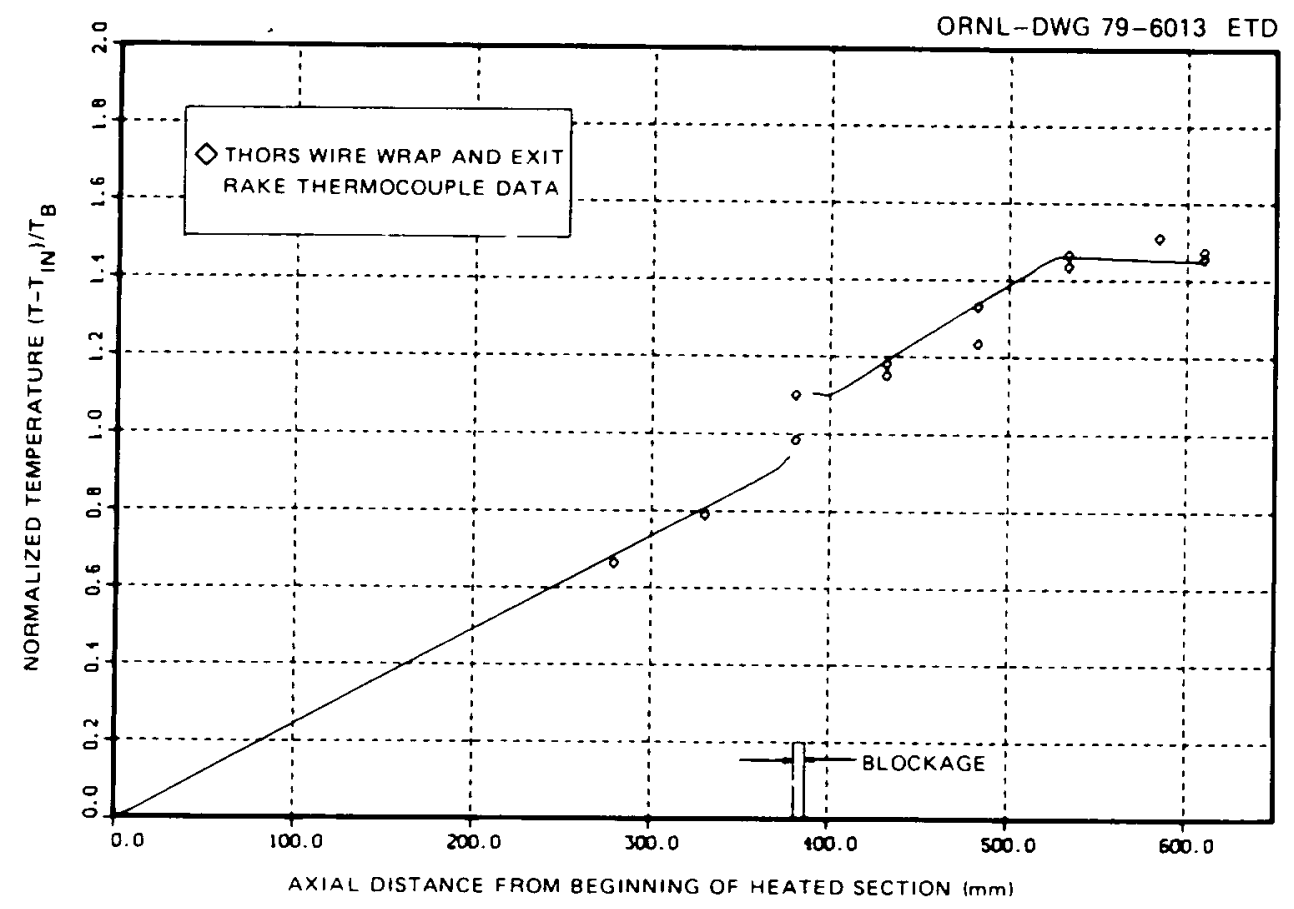

Fig. 6. Normalized temperature vs axial position, subchannel type $B$, SABRE-1 (FMIX $=1.0$ ) computation and THORS data at $100 \%$ nominal flow (test 2 , run 101 , bund le $3 A$ ).

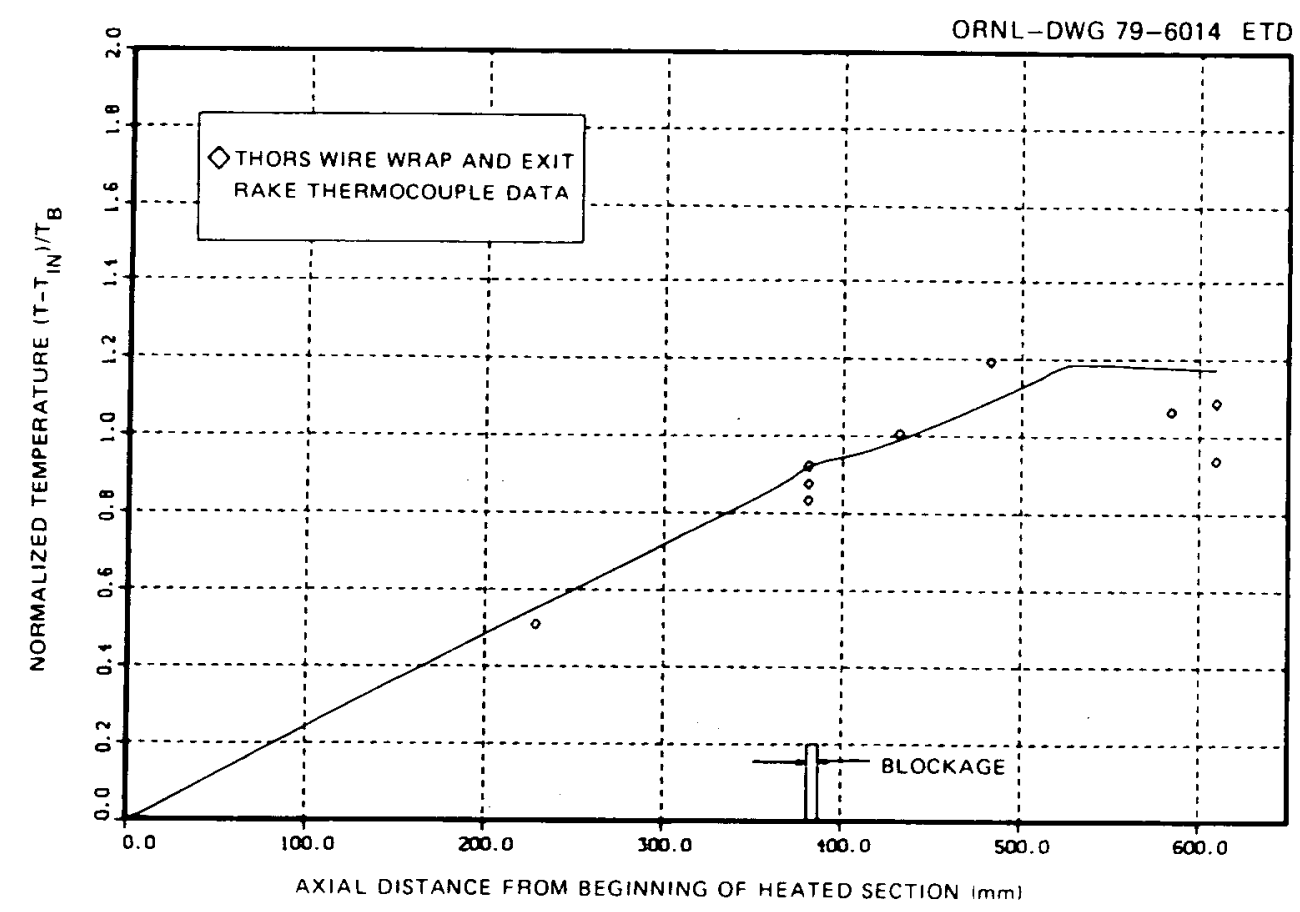

Fig. 7. Normalized temperature vs axial position, subchannel type 1E, SABRE-1 (FMIX $=1.0$ ) computation and THORS data at $100 \%$ nominal flow (test 2 , run 101 , bund le $3 A$ ). 


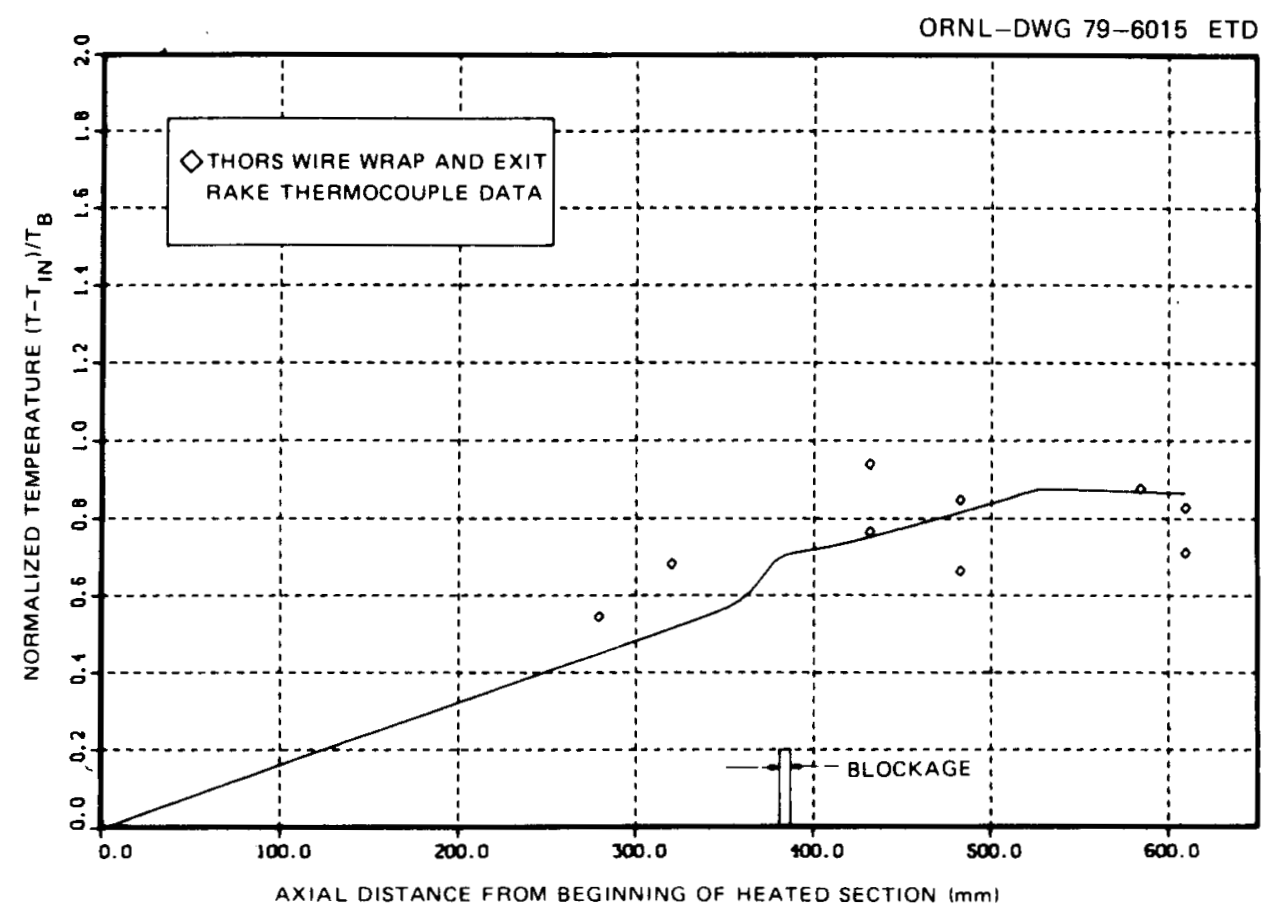

Fig. 8. Normalized temperature vs axial position, subchannel type 2EC, SABRE-1 (FMIX = 1.0) computation and THORS data at $100 \%$ nominal flow (test 2 , run 101 , bundle $3 A$ ).

The results of using SABRE-1A to model run 101 with FMIX $=1.0$ are shown in Fig. 9 for subchannel type B. SABRE-1A and SABRE-1 have different turbulent mixing correlations, and, as shown in Fig. 9, using FMIX = 1.0 induces too much mixing downstream of the blockage. Reducing FMIX to zero gives too little mixing, as seen in Fig. 10. A value of 0.3 seems to give best agreement for this case, as shown in Fig. 11 .

Figures 12 and 13 show results for subchannel types $1 \mathrm{E}$ and $2 \mathrm{EC}$, respectively, for run 101 with FMIX $=0.3$. Agreement is good, considering the limitations of the one-sixth section model.

Figures 14,15 , and 16 show results for subchannel types $B, 1 E$, and $2 \mathrm{EC}$, respectively, for run 104 ( $80 \%$ nominal flow) with FMIX $=0.3$. Agreement is good, with Fig. 14 suggesting an appropriate value of FMIX between 0 and 0.3. Figures 17, 18, and 19 show results for subchannel types $B$, $1 \mathrm{E}$, and $2 \mathrm{EC}$, respectively, for run 107 (60\% nominal flow). Again, agreement is good, with Fig. 17 suggesting that a value of FMIX slightly lower than 0.3 might improve the comparison. 


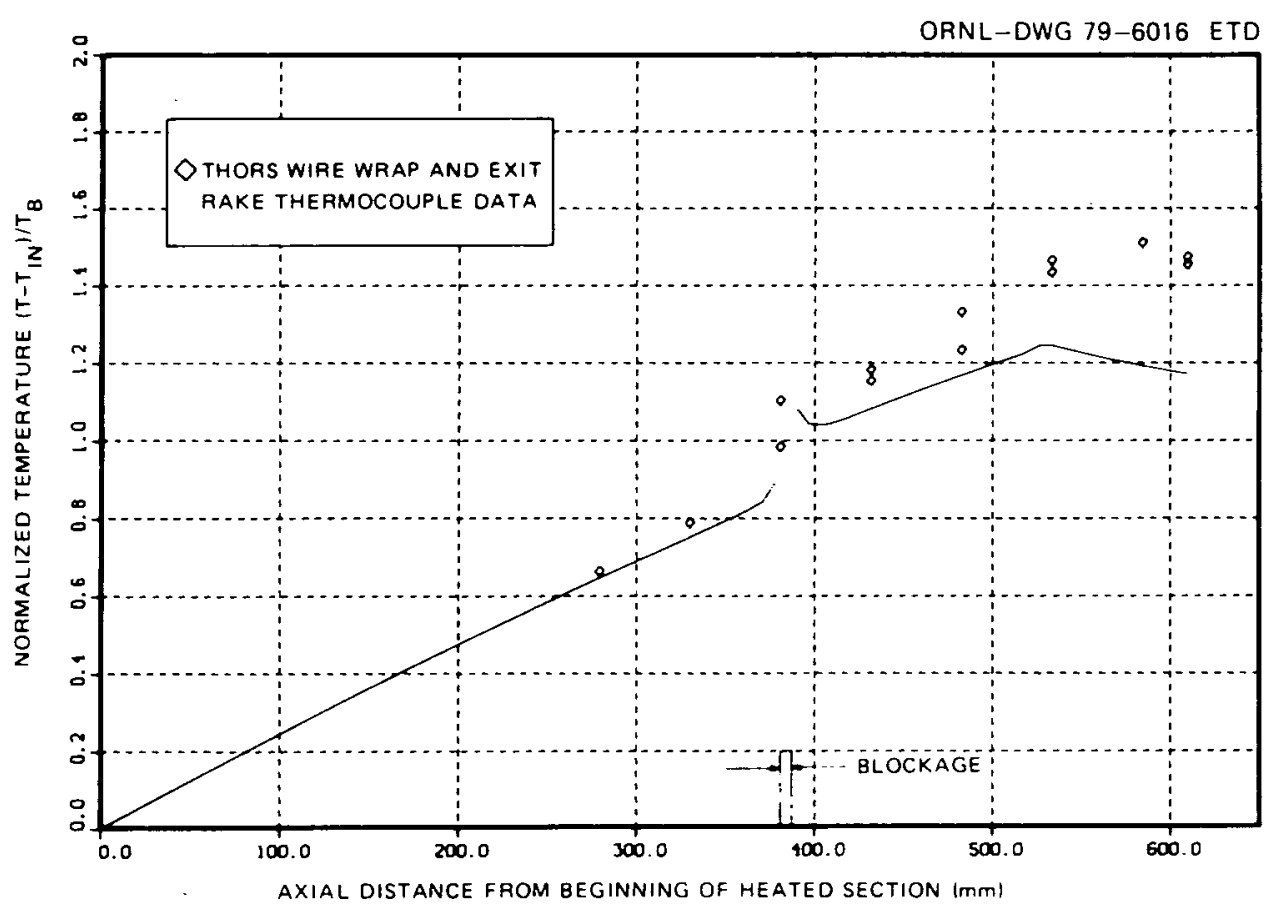

Fig. 9. Normalized temperature vs axial position, subchannel type B, SABRE-1A (FMIX $=1.0$ ) computation and THORS data at $100 \%$ nominal flow (test 2, run 101 , bundle $3 \mathrm{~A}$ ).

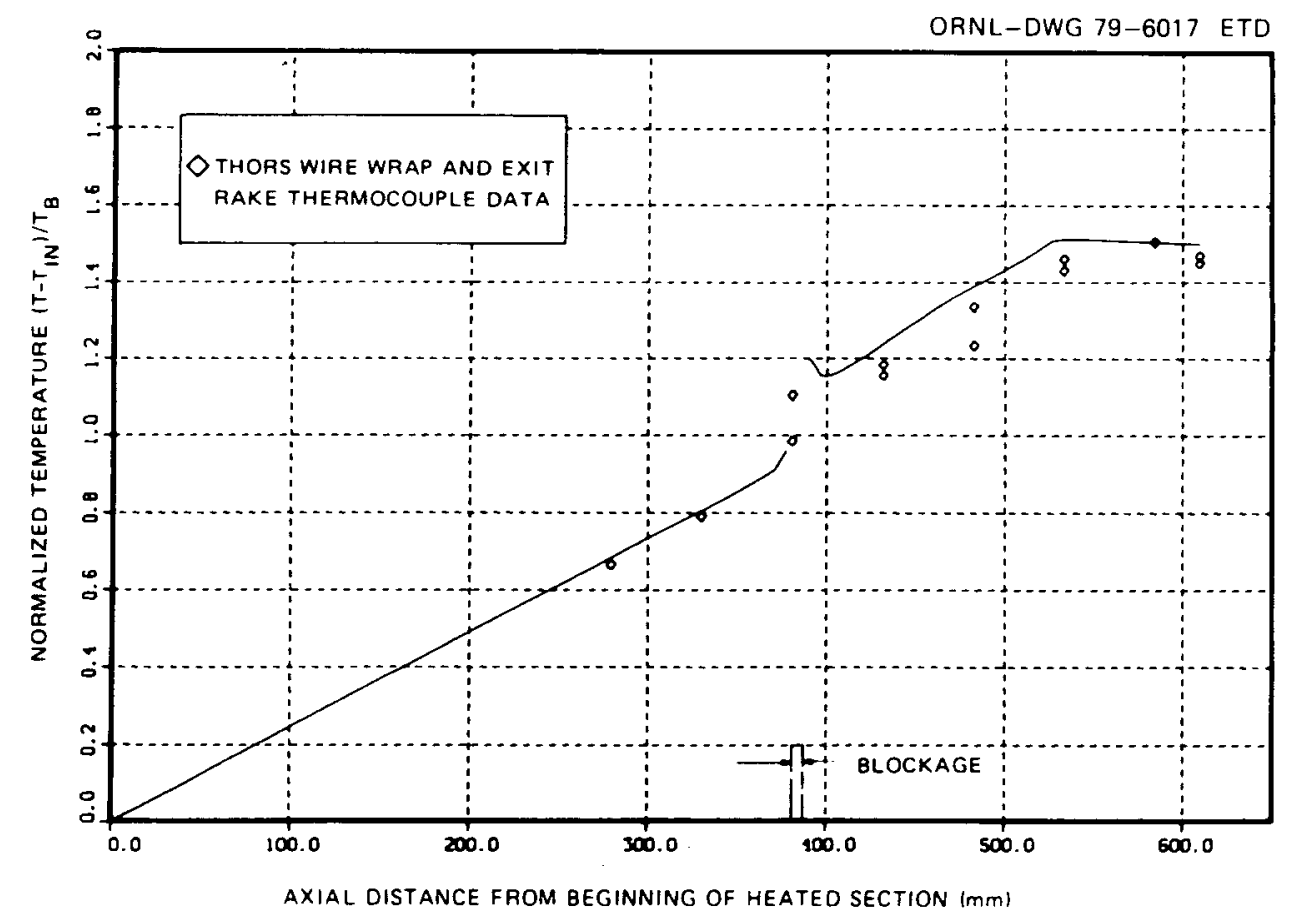

Fig. 10. Normalized temperature vs axial position, subchannel type B, SABRE-1A (FMIX $=0.0$ ) computation and THORS data at $100 \%$ nominal flow (test 2, run 101 , bundle $3 A$ ). 


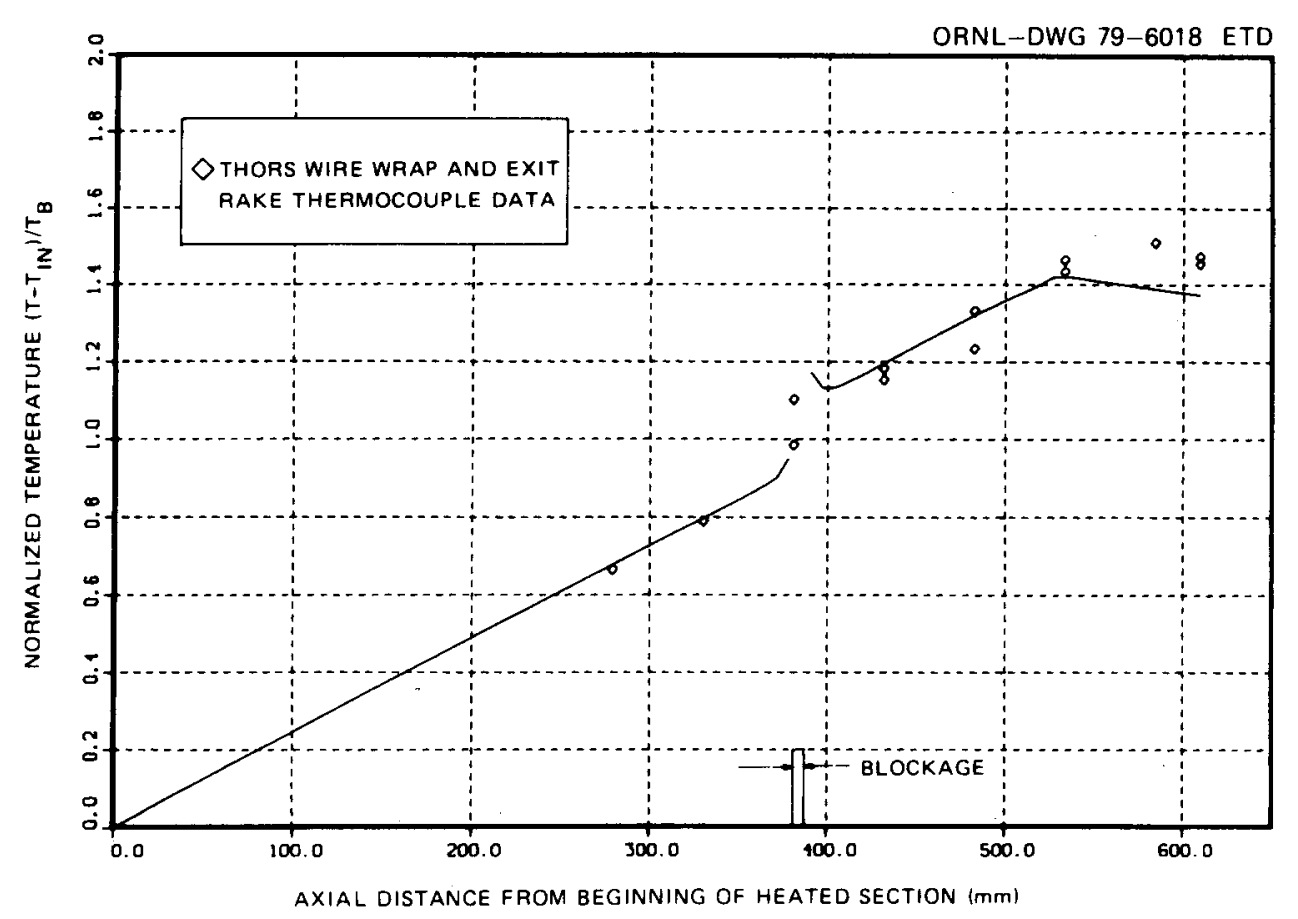

Fig. 11. Normalized temperature vs axial position, subchannel type $B$, SABRE-1A (FMIX $=0.3$ ) computation and THORS data at $100 \%$ nominal flow (test 2, run 101 , bundle $3 A$ ).

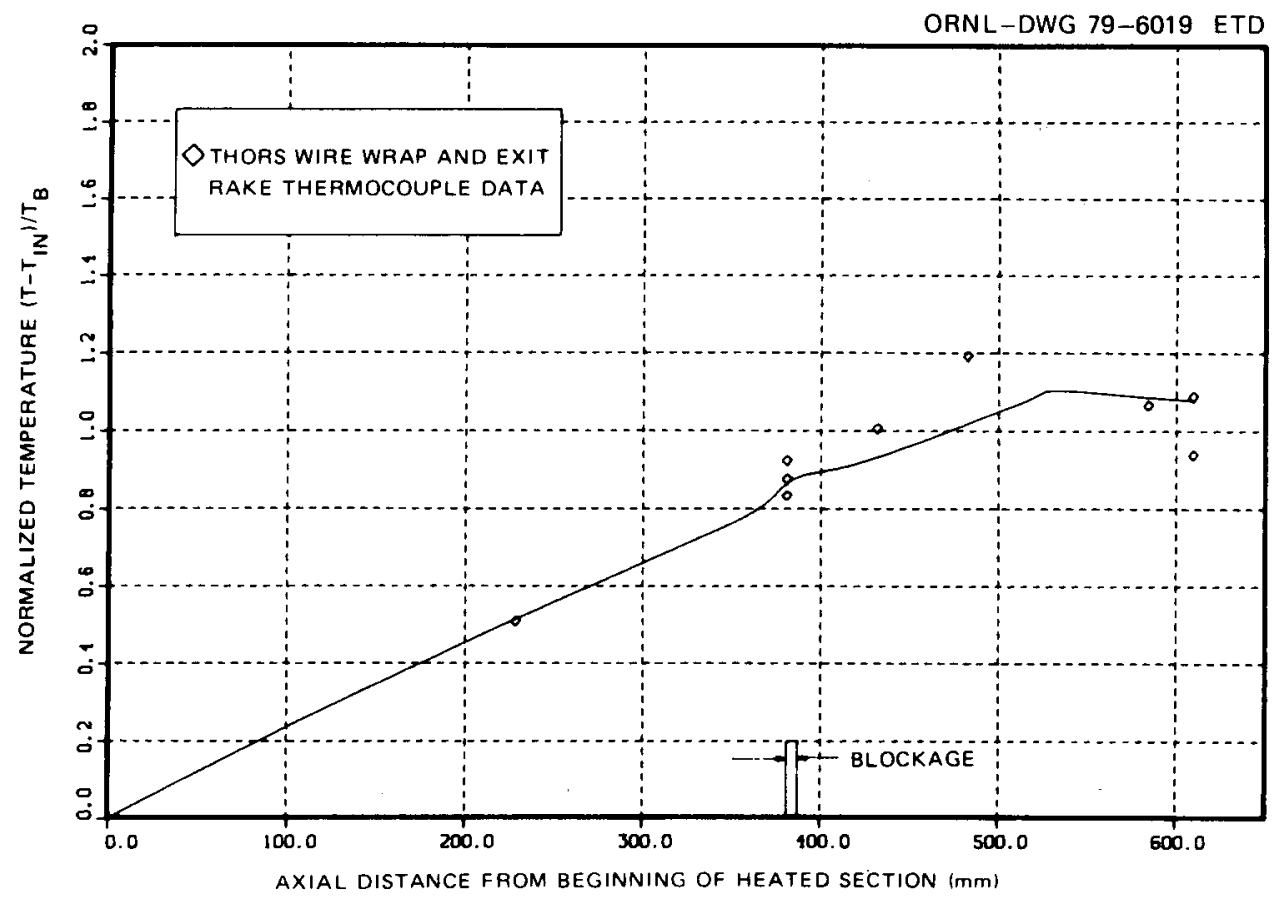

Fig. 12. Normalized temperature vs axial position, subchannel type 1E, SABRE-1A (FMIX $=0.3$ ) computation and THORS data at $100 \%$ nominal flow (test 2, run 101 , bund le $3 A$ ). 


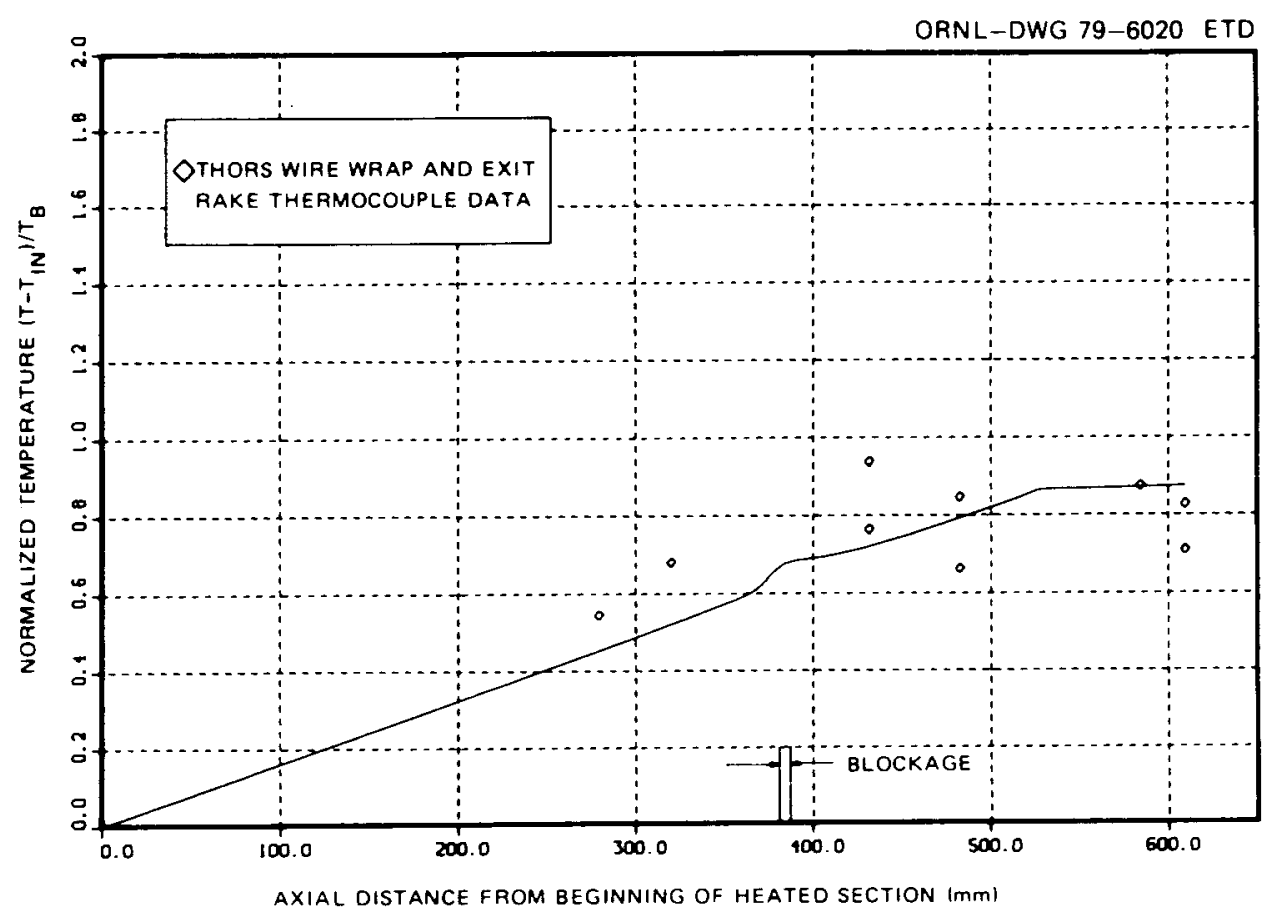

F1g. 13. Normalized temperature vs axial position, subchannel type 2EC, SABRE-1 (FMIX $=0.3$ ) computation and THORS data at $100 \%$ nominal flow (test 2, run 101 , bundle $3 A$ ).

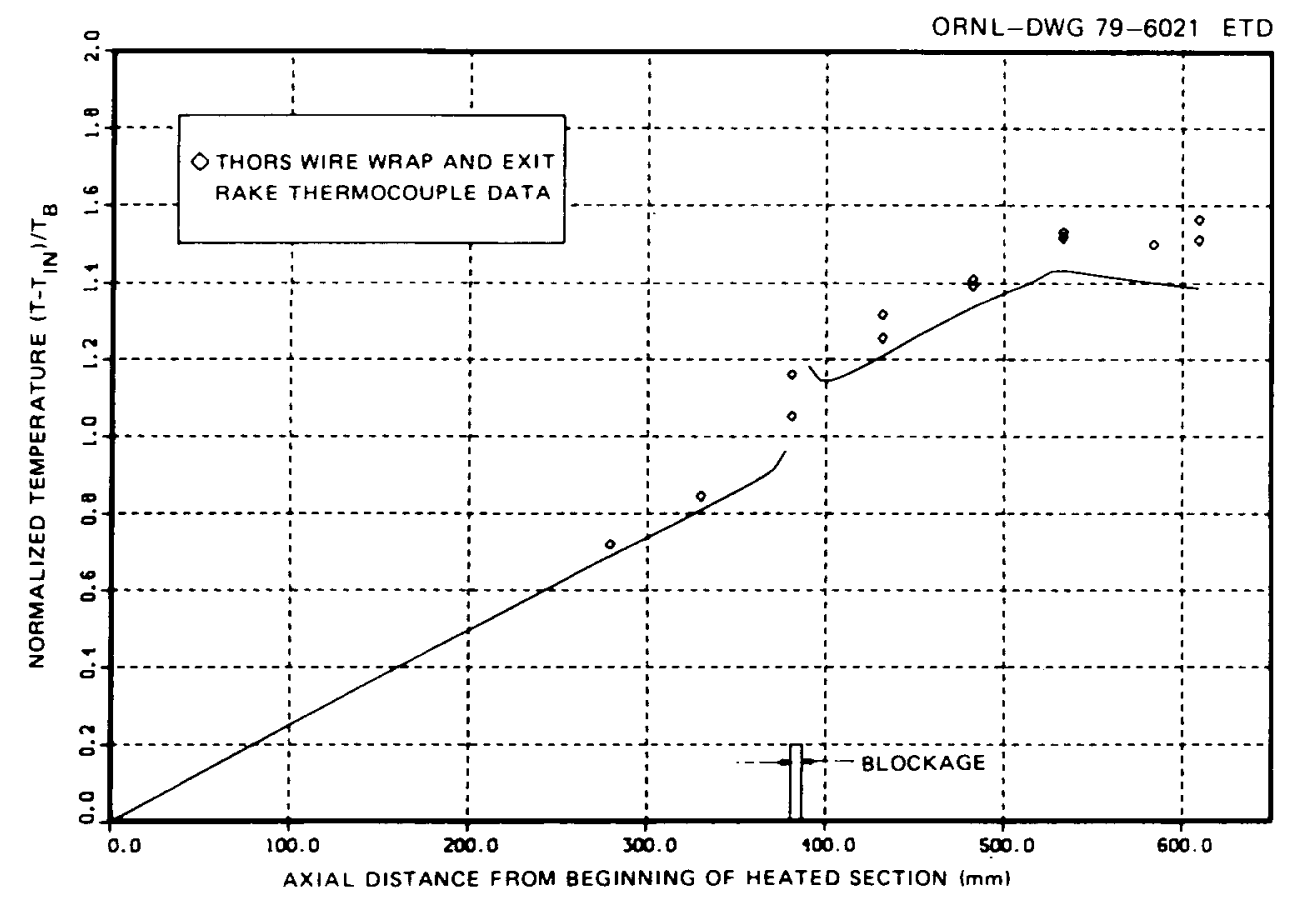

Fig. 14. Normalized temperature vs axial position, subchannel type $B$, SABRE-1A (FMIX $=0.3$ ) computation and THORS data at $80 \%$ nominal flow (test 2 , run 104 , bundle $3 \mathrm{~A}$ ). 


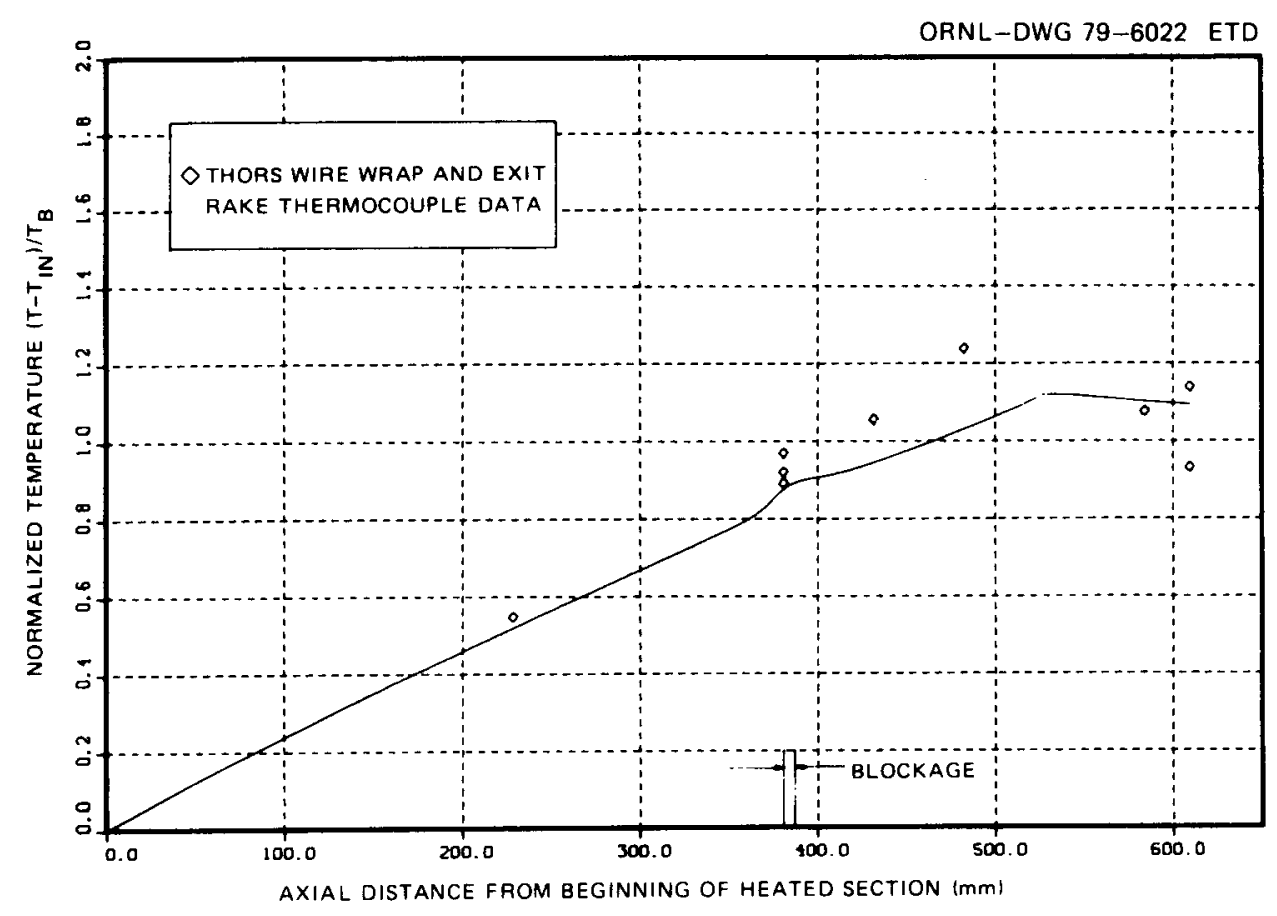

Fig. 15. Normalized temperature vs axial position, subchannel type 1E, SABRE-1A (FMIX $=0.3$ ) computation and THORS data at $80 \%$ nominal flow (test 2, run 104, bundle $3 A$ ).

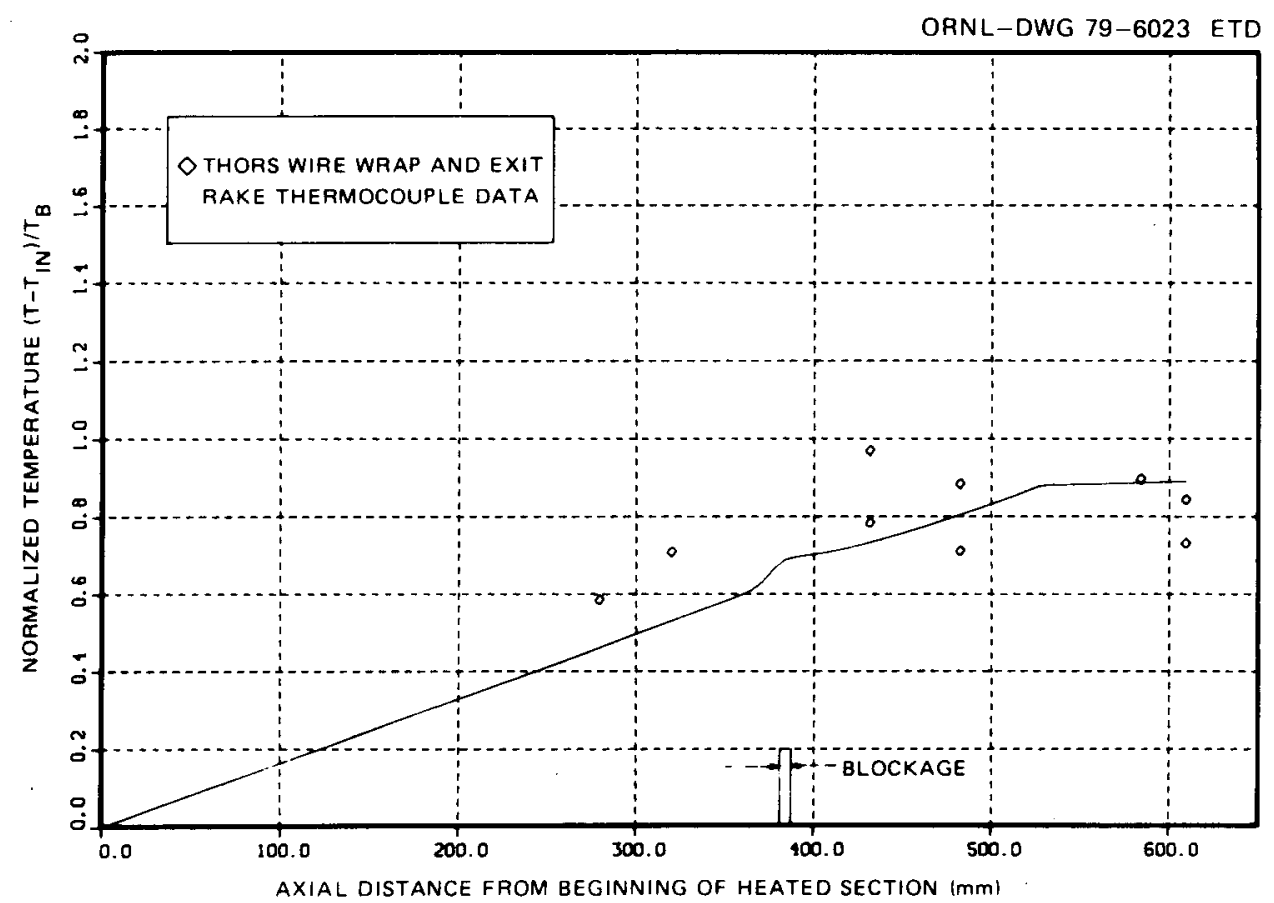

Fig. 16. Normalized temperature vs axial position, subchannel type 2EC, SABRE-1A (FMIX $=0.3$ ) computation and THORS data at $80 \%$ nominal flow (test 2, run 104, bundle $3 A$ ). 


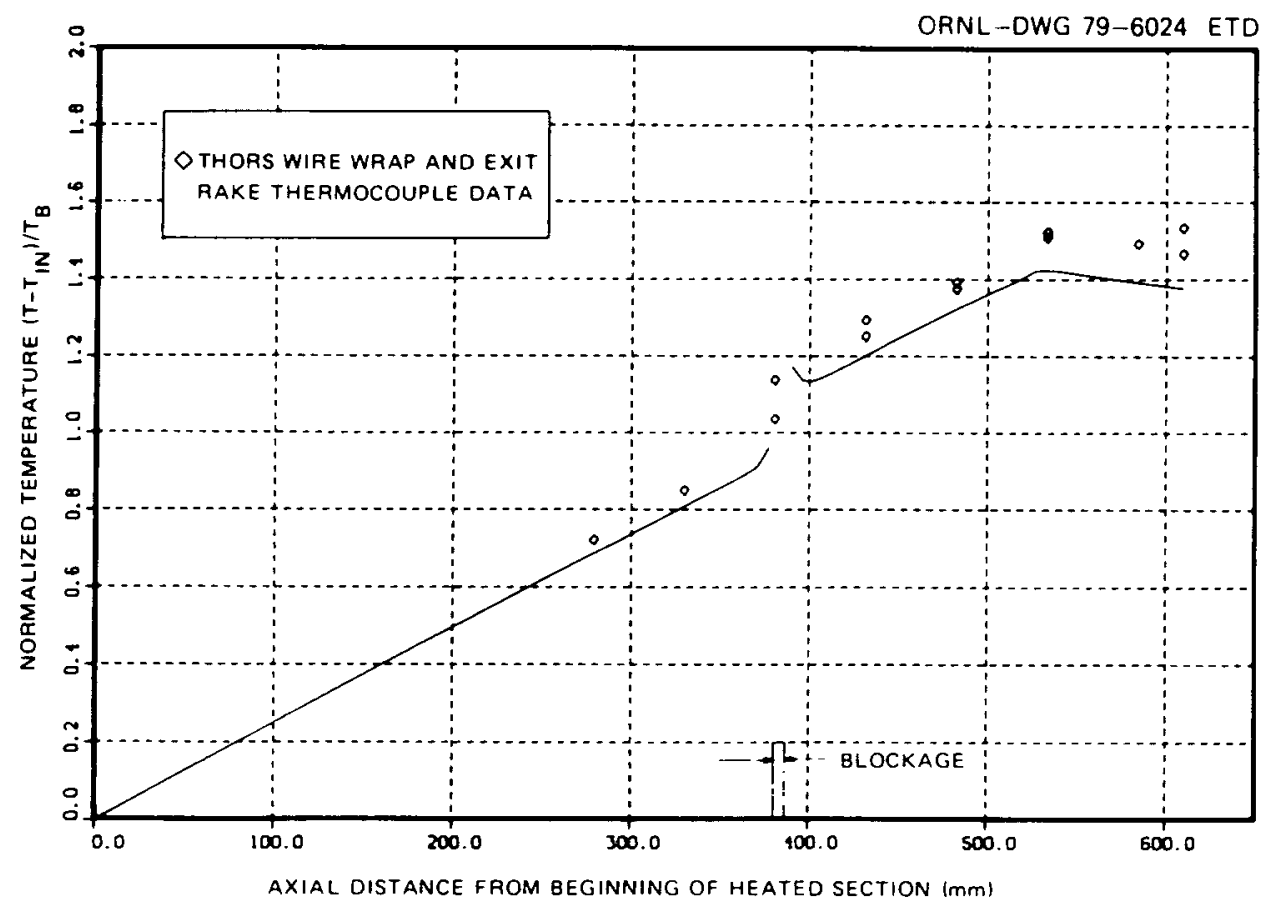

Fig. 17. Normalized temperature vs axial position, subchannel type B, SABRE-1A (FMIX $=0.3$ ) computation and THORS data at $60 \%$ nominal flow (test 2 , run 107 , bund le $3 A$ ).

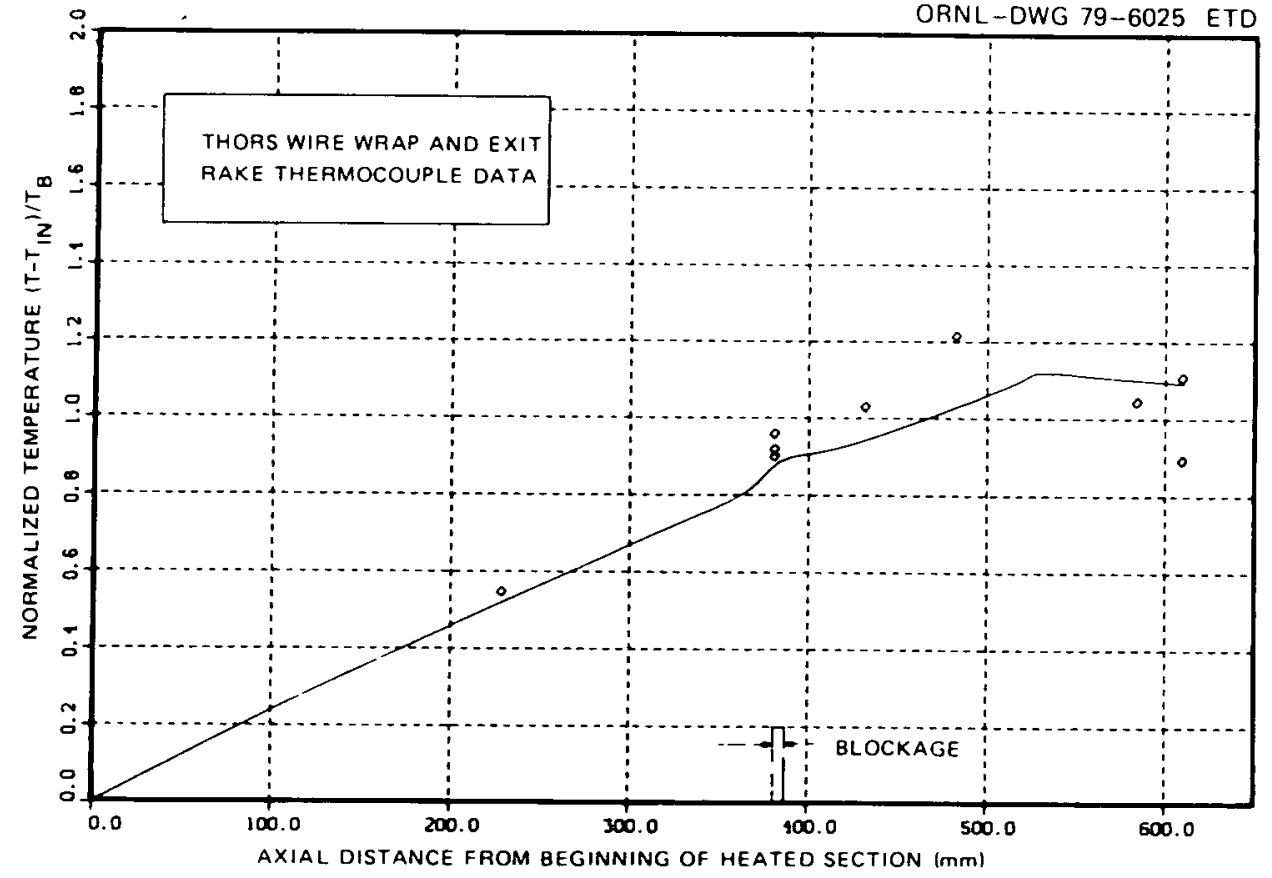

Fig. 18. Normalized temperature vs axial position, subchannel type 1E, SABRE-1A (FMIX $=0.3$ ) computation and THORS data at $60 \%$ nominal flow (test 2, run 107, bund le $3 A$ ). 


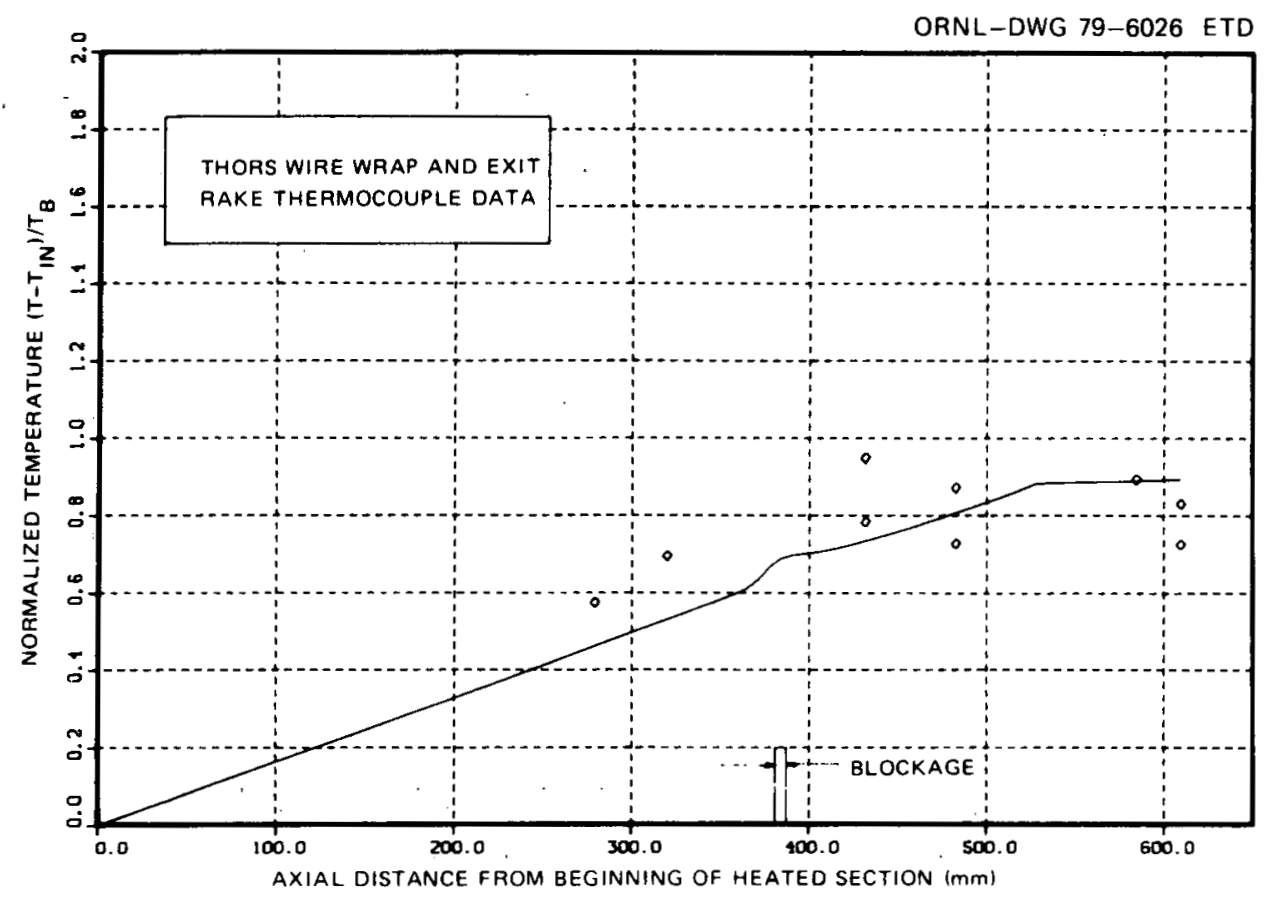

Fig. 19. Normalized temperature vs axial position; subchannel type 2EC, SABRE-1 (FMIX $=0.3$ ) computation and THORS data at $60 \%$ nominal flow (test 2, run 107, bundle $3 A$ ). 
5. DESCRIPTION OF THORS BUNDLE 5A

THORS bundle 5A consisted of 19 electric cartridge heaters with outside diameters of $5.8 \mathrm{~mm}(0.23 \mathrm{In}$.) which were spaced by $1.4-\mathrm{mm}$-diam (0.056-in.) wire-wrap spacers on a 305-mm (12-1n.) pitch. A 3.2-mm-thick (0.125-in.) stainless steel blockage plate blocked $35 \%$ of the total flow area $102 \mathrm{~mm}$ ( $4 \mathrm{in}$ ) ) into the $457-\mathrm{mm}\left(18-\mathrm{n}_{\bullet}\right)$ heated section. The positions of the edge blockage and wire-wrap thermocouple instrumentation are shown in Fig. 20. Half-size wire wraps were used adjacent to the duct wall to decrease the flow area in the edge subchannels and to flatten the radial temperature profile. Figure 21 shows the test section

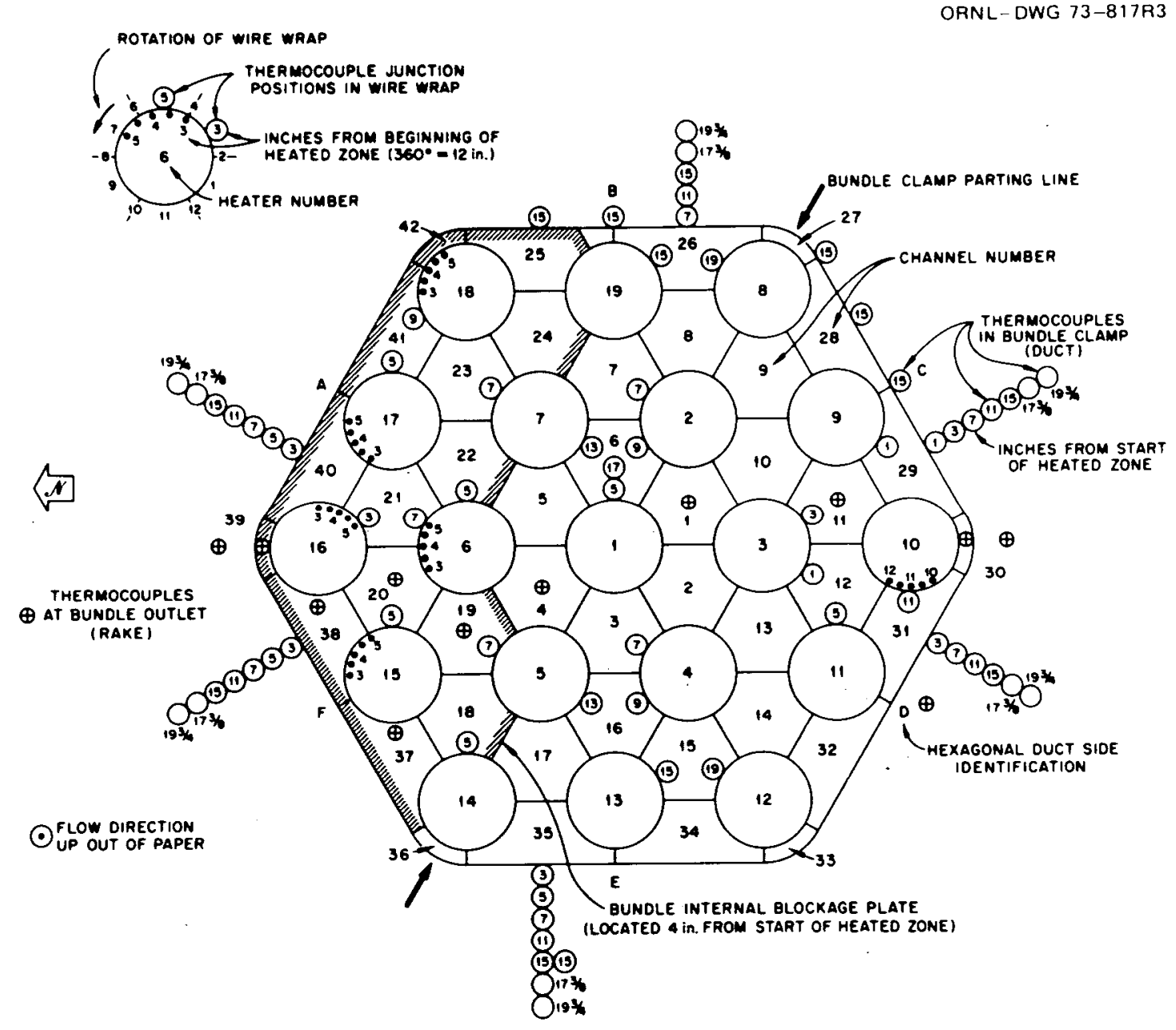

Fig. 20. Cross section of THORS bundle 5A showing location of blockage plate and thermocouple instrumentation ( $1 \mathrm{in} .=25.4 \mathrm{~mm}$ ). 


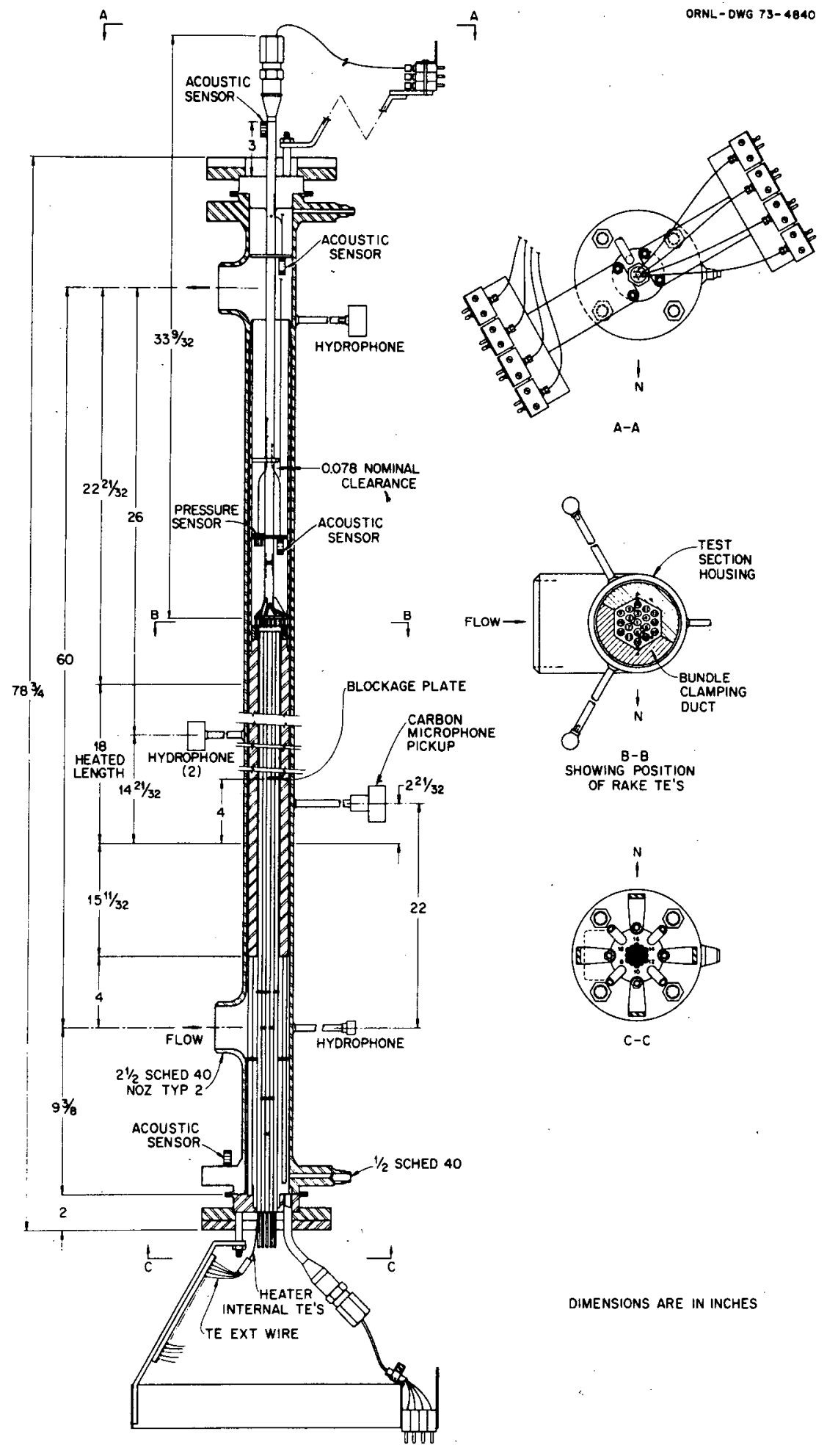

F1g. 21. THORS bundle 5A test section assembly $(11 \mathrm{n} .=25.4 \mathrm{~mm})$. 
assembly. A complete description of bundle 5A, along with experimental data, may be found in Ref. 5 .

Most of the bundle 5A test program was run with fuel pin simulator No. 16 (Fig. 20) and all heater-internal thermocouples inoperative (they became inoperative during bundle fabrication and assembly). The bundle was rebuilt and designated bund $1 \mathrm{e} 5 \mathrm{~B}$, and a more extensive test program was run. Initial comparative analysis (Ref. 6) used bundle 5B data and the SABRE-1 code. Comparison of data from bundles $5 \mathrm{~A}$ and $5 \mathrm{~B}$ indicates, however, that there was probaby a small leakage between the duct wall and the blockage plate in bundle 5B, lowering temperatures in the wake region. For this reason, bundle $5 \mathrm{~A}$ data are used here. No power was applied to fuel pin simulator No. 16 in the SABRE model. 


\section{SABRE MODEL OF THORS BUNDLE 5A}

The computational mesh begins at the beginning of the heated section and ends $203 \mathrm{~mm}$ ( $8 \mathrm{in}$.) into the heated section. The $3.2 \mathrm{~mm}$-thick (0.125-in.) blockage plate is located $102 \mathrm{~mm}$ ( $4 \mathrm{in.}$ ) into the heated section, midway in the computational mesh. Experimentation indicated that these inlet and outlet boundaries are far enough from the blockage so as not to significantly affect the flow solution near the blockage. The axial nodes are a uniform $6.35 \mathrm{~mm}(0.25 \mathrm{in.})$ in length, twice the thickness of the blockage plate. Ideally, the axial node size should be the same or smaller than the blockage thickness, but machine storage limitations prohibit this here. Again, experimentation indicated the flow soiution was not significantly affected by using a $6.35-\mathrm{mm}$ axial node. Machine storage requirements are $\sim 430 \mathrm{~K}$, and $\sim 5-$ to 10 -min running time is required for satisfactory convergence on an IBM 360/91. SABRE-1A cases require results from $S A B R E-1$ cases as initial flow conditions.

A cross section of the SABRE bundle $5 \mathrm{~A}$ model is shown in Fig. 22. Note the outline of the blockage plate and the location of the $\mathrm{x}$ and $\mathrm{y}$ coordinate axis, which will be used in three-dimensional temperature plots in the next section. Two cross sections are also shown, one cutting across the central row of pins (cross section one) and the other cutting through the edge channels on the left side of the bundle (side view). Two-dimensional flow fields will be given at these two cross sections.

The following comments on SABRE modeling, discussed in Sect. 3, also apply here.

1. SABRE provides a detailed model of the flow geometry of bundle 5A except for wire-wrap forced-diversion crossflow. Subchannel flow areas and wetted perimeters are corrected, nondirectional thermal mixing is covered by the mixing correlation factor FMIX, but directional wirewrap flow sweeping is not included.

2. The blockage in bundle $5 \mathrm{~A}$ is not symmetrical about a one-sixth section, so a full bundle model must be used.

3. Inlet velocity boundary condition (meters per second) is used.

4. Default values of all parameters are used except for FMIX and GAMBL. 


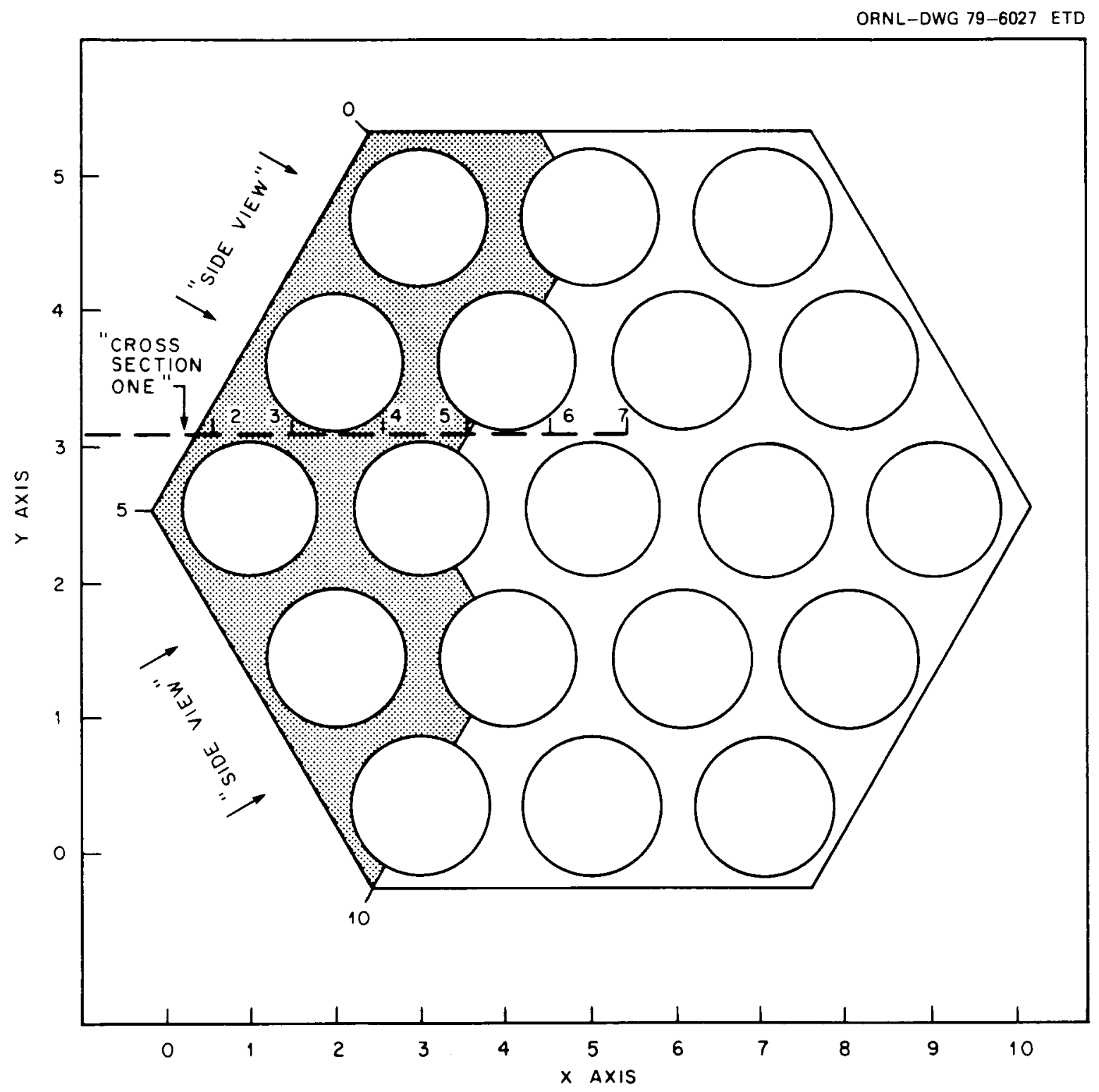

Fig. 22. Cross section of THORS bundle 5A showing locations of two cross sections and $x, y$ indexing scheme. 
7. COMPARISON OF SABRE RESULTS WITH THORS BUNDLE 5A DATA

SABRE results and THORS data are compared for three runs, representing $\sim 100,40$, and 10\% nominal flow. Table 2 gives experimental conditions for these three cases: runs 151,158 , and 162 of test 2 , series 4 of the bundle $5 \mathrm{~A}$ test program (Ref. 5). Fuel pin simulator No. 16 is not functional for these runs (as explained in Sect. 5); subchannel power distribution in SABRE is adjusted to represent this.

Table 2. Experimental conditions for three runs of test 2 , series 5 , bundle $5 \mathrm{~A}$ test program

\begin{tabular}{lccccc}
\hline $\begin{array}{c}\text { Run } \\
\text { No. }\end{array}$ & $\begin{array}{c}\text { Approximate } \\
\text { nominal } \\
\text { flow } \\
(\%)\end{array}$ & $\begin{array}{c}\text { Inlet flow } \\
(1 \text { iters sec }\end{array}$ & $\begin{array}{c}\text { Power/pin } \\
(\mathrm{kW})\end{array}$ & $\begin{array}{c}\text { Inlet } \\
\text { temperature } \\
\left({ }^{\circ} \mathrm{C}\right)\end{array}$ & $\begin{array}{c}\text { Bulk } \\
\text { temperature } \\
\text { rise, T } \\
\left({ }^{\circ} \mathrm{C}\right)\end{array}$ \\
\hline 151 & 100 & 2.63 & 7.40 & 326 & 45 \\
158 & 40 & 1.08 & 7.59 & 326 & 110 \\
162 & 10 & 0.31 & 5.53 & 242 & 274 \\
\hline
\end{tabular}

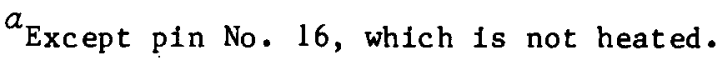

The SABRE flow field near the blockage is shown in Figs. 23 and 24 for run 151 (nominal flow). Referring to Fig. 22, the cross section one is shown in Fig. 23 and the side view in Fig. 24. The recirculation zone extends to $\sim 165 \mathrm{~mm}$ (from the beginning of the heated zone), or $\sim 60$ $\mathrm{mm}$ behind the blockage plate. Relative velocities are indicated by vector lengths, except where only the tip remains. Note that these plots are two-dimensional cross sections of a three-dimensional flow. The center of the recirculation zone appears to be at 120 to $130 \mathrm{~mm}$, which is close to the $127-\mathrm{mm}$ ( $5-\mathrm{in}$.) location of wire-wrap thermocouples that are used in comparative analysis.

The SABRE flow field for run 158 ( $40 \%$ flow) is shown in Figs. 25 (cross section one) and 26 (side view). The recirculation zone is very similar to that of run 151 (100\% flow), but slightly shorter. In this case, it extends to $\sim 155 \mathrm{~mm}$, or $\sim 50 \mathrm{~mm}$ from the blockage plate.

The SABRE flow field for run $162(10 \%$ flow) is shown in Figs. 27 (cross section one) and 28 (side view). The recirculation zone is again 


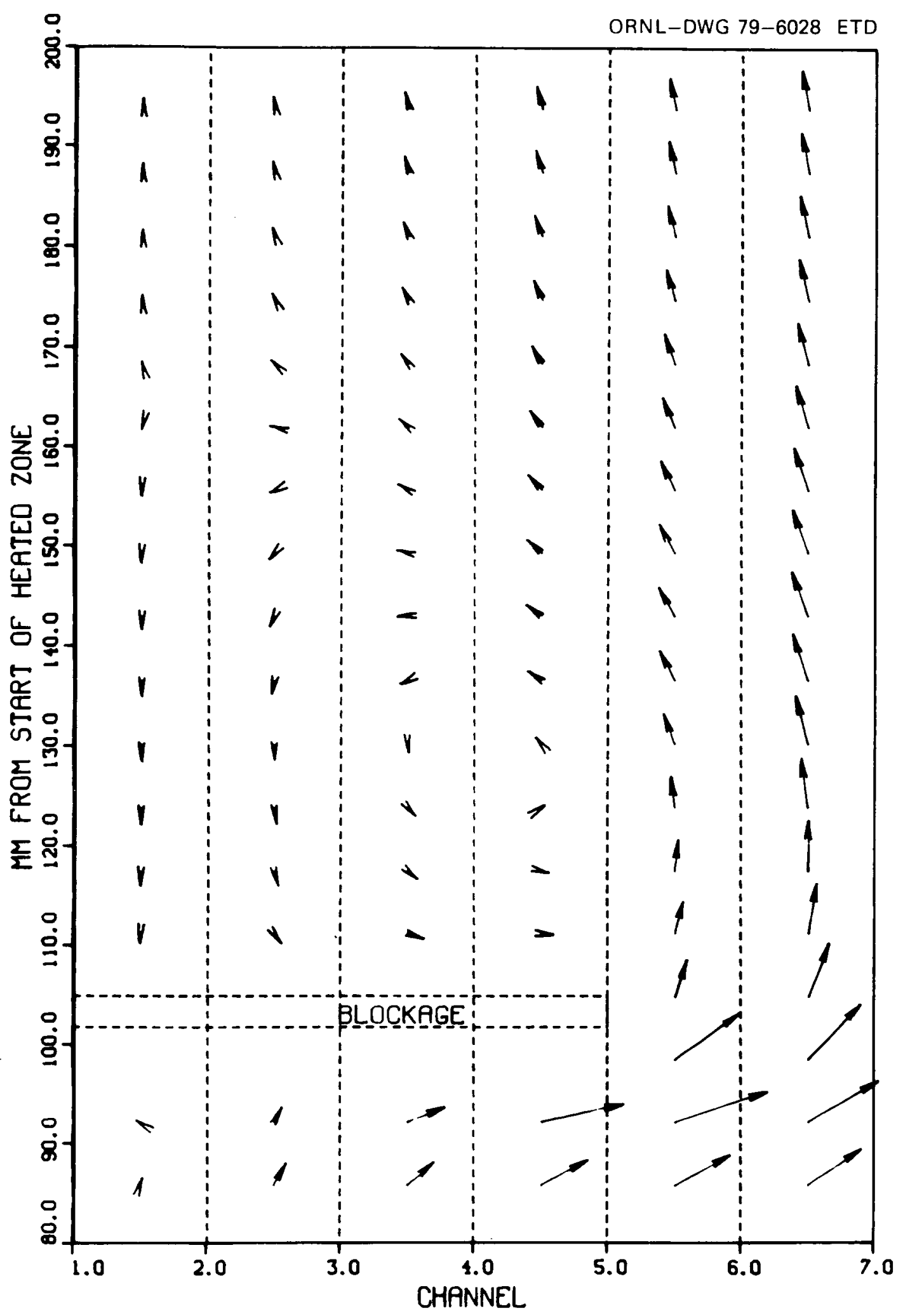

Fig. 23. SABRE-1A computed flow field (cross section one) at nominal flow (test 2, run 151, bundle 5A). 


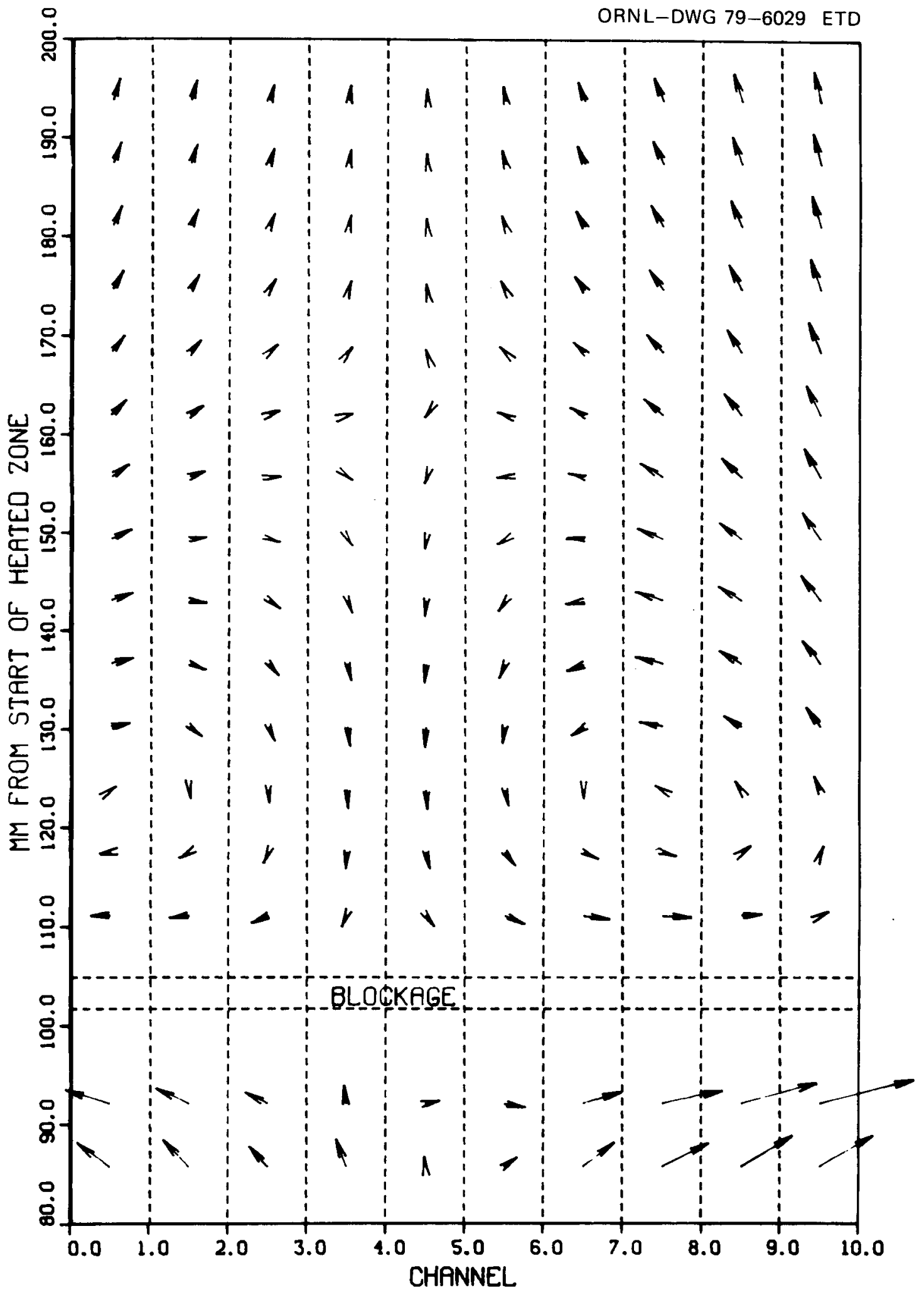

Fig. 24. SABRE-1A computed flow field (side view) at nominal flow (test 2, run 151, bundle 5A). 


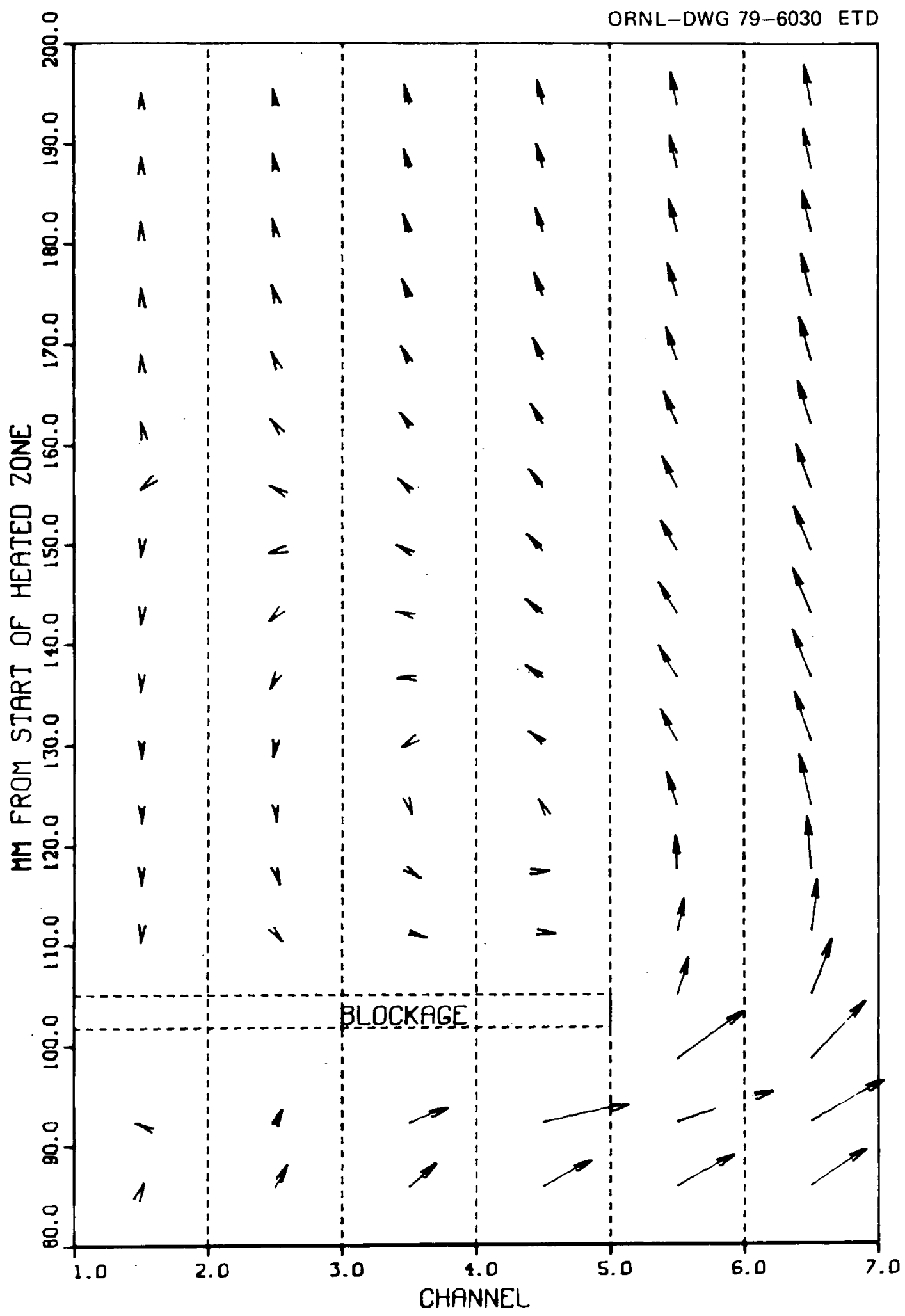

Fig. 25. SABRE-1A computed flow field (cross section one) at $40 \%$ nominal flow (test 2, run 158, bundle 5A). 


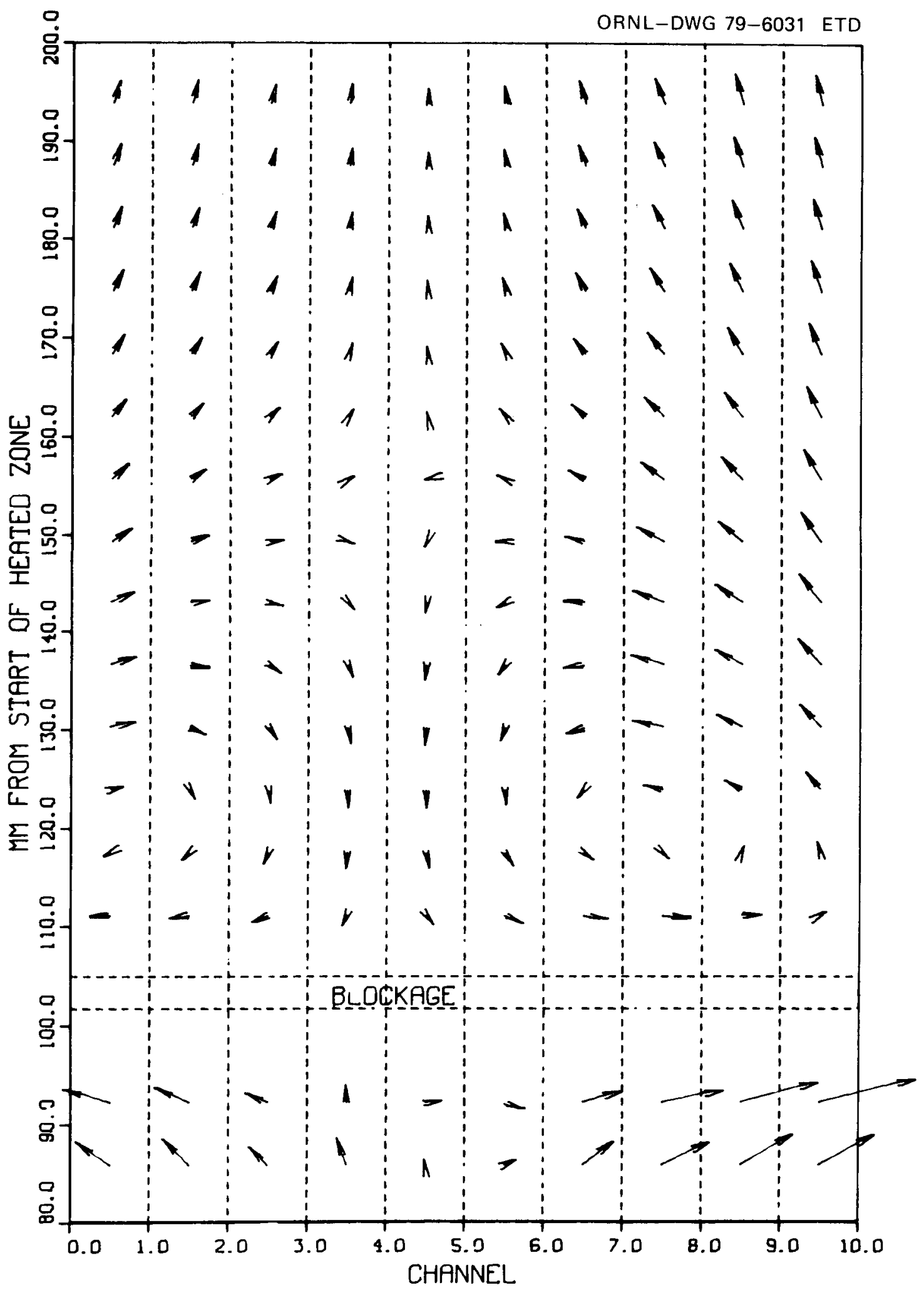

Fig. 26. SABRE-1A computed flow field (side view) at $40 \%$ nominal flow (test 2, run 158, bundle 5A). 


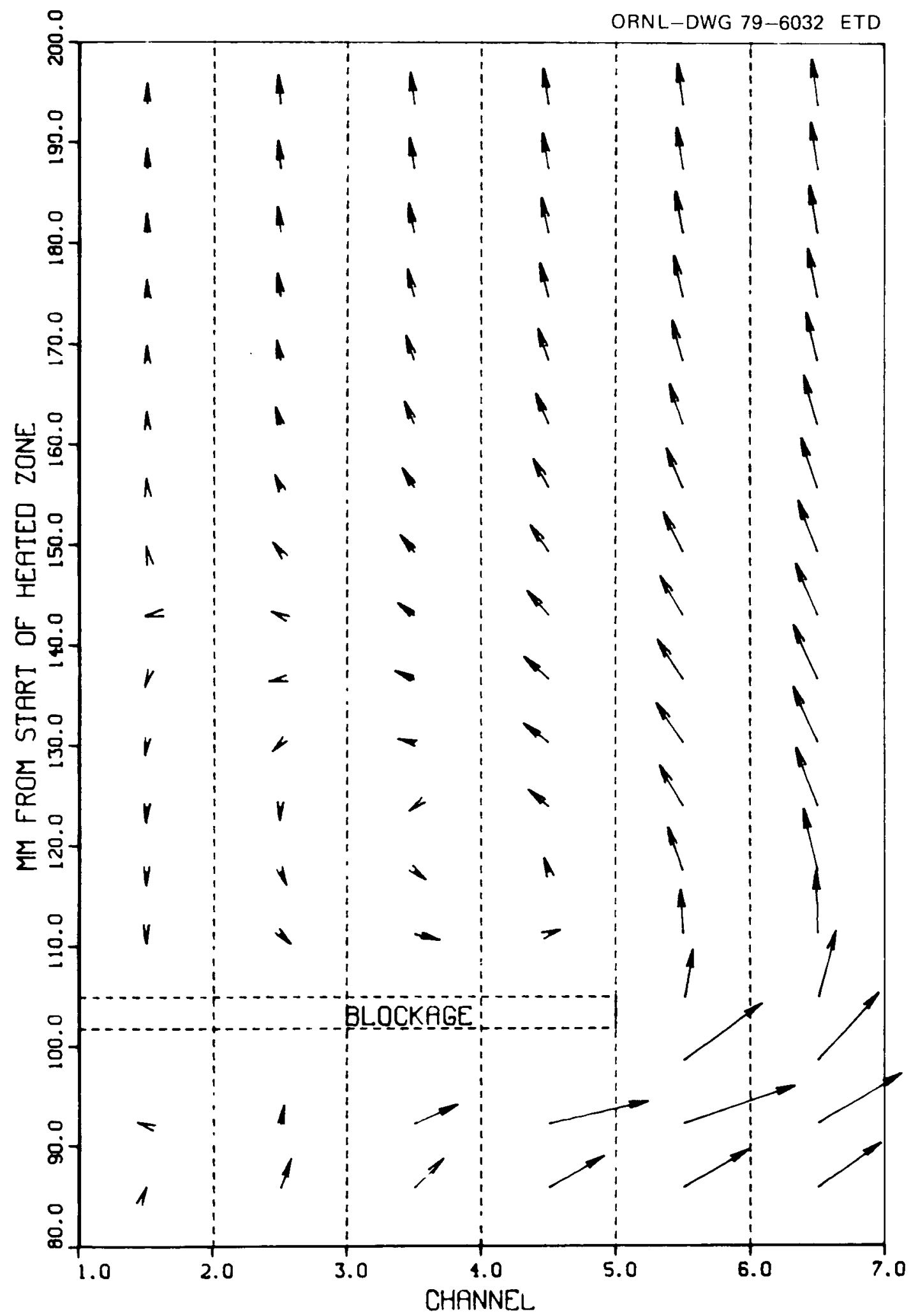

Fig. 27. SABRE-1A computed flow field (cross section one) at $10 \%$ nominal flow (test 2, run 162, bundle 5A). 


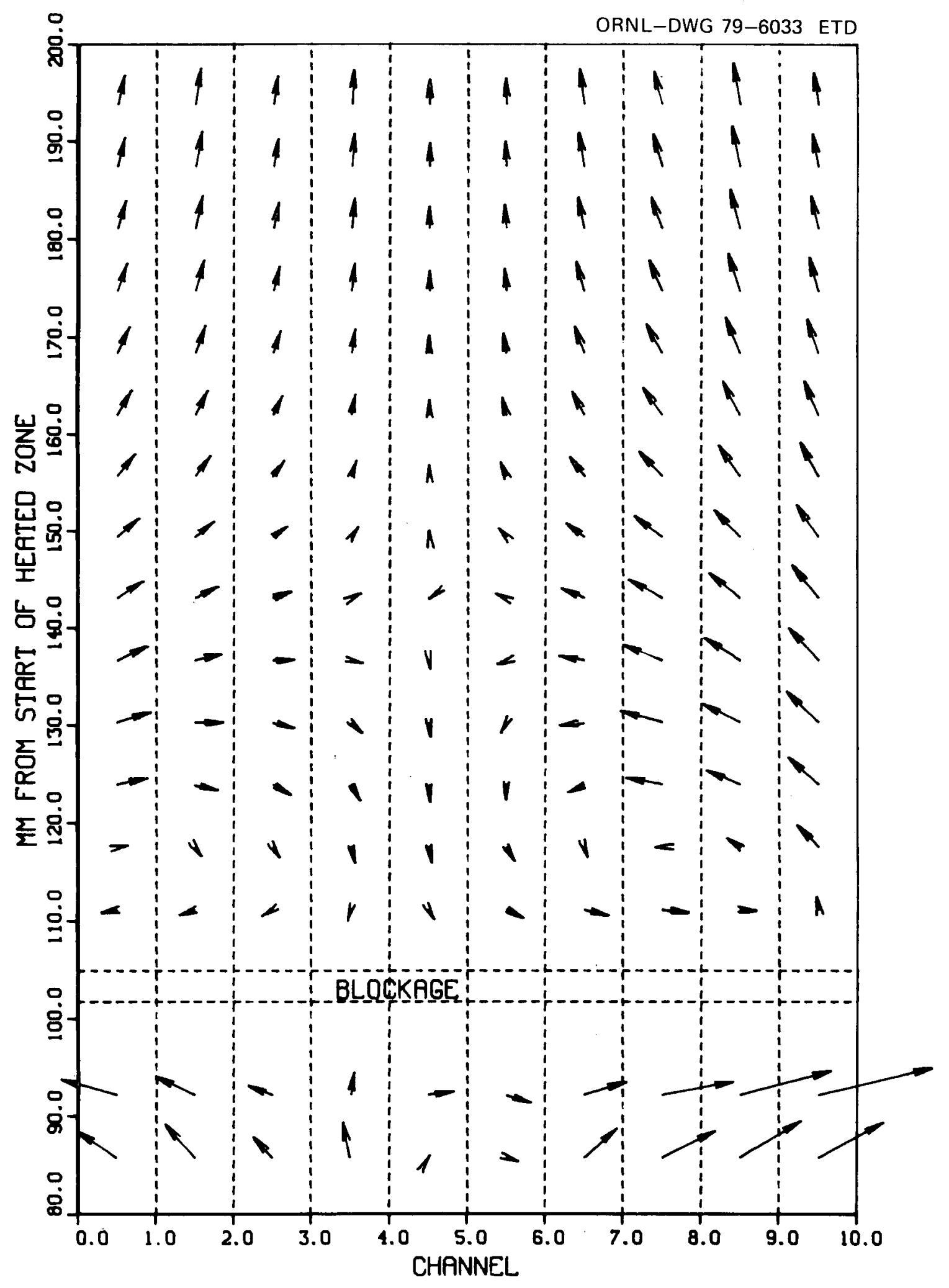

Fig. 28. SABRE-1A computed flow field (side view) at $10 \%$ nominal flow (test 2, run 162, bundle 5A). 
slightly shorter, extending to $\sim 145 \mathrm{~mm}$, or $\sim 40 \mathrm{~mm}$ behind the blockage plate.

SABRE temperatures at $127 \mathrm{~mm}$ ( $5 \mathrm{in}$ ) are compared with bundle $5 \mathrm{~A}$ wire-wrap data using three-dimensional plots of normalized temperature $\left[\left(\mathrm{T}-\mathrm{T}_{i n}\right) / \mathrm{T}_{\mathrm{B}}\right]$ vs position in the $\mathrm{x}, \mathrm{y}$ coordinate mesh shown in Fig. 22 . The surface plotted in Fig. 29 represents the SABRE-1A temperature field at $127 \mathrm{~mm}$ (near the center of the recirculation zone). Vectors are drawn from the surface to the location of experimental data points. These are wire-wrap thermocouple data points, except for the two with Ds near the vector head, which are duct wall thermocouple data. Duct wall thermocouples are slightly offset from the subchannel sodium flow and are less

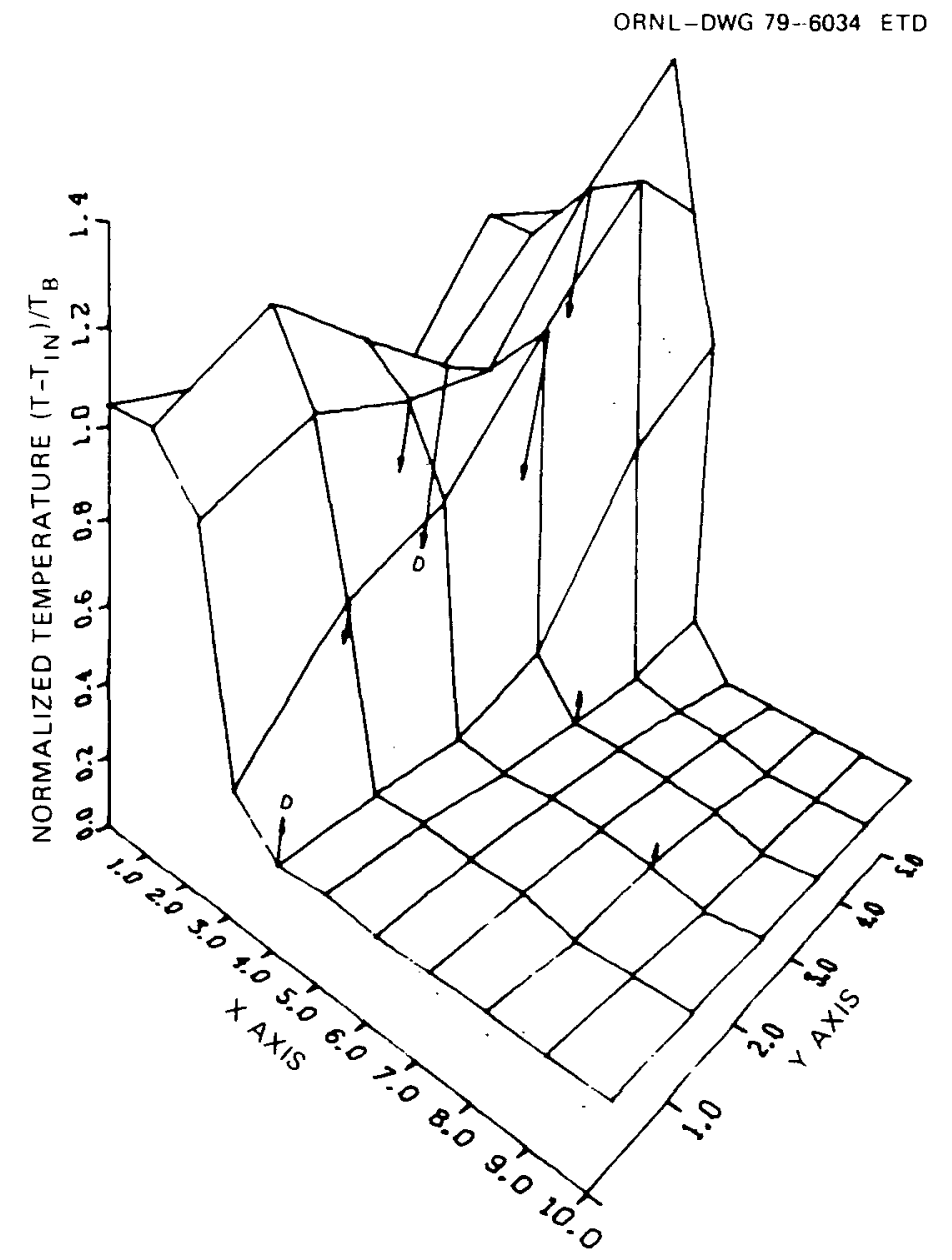

Fig. 29. Comparison of SABRE-1A and experimental data (shown by vectors) at $100 \%$ nominal flow, FMIX $=1.0$ (test 2, run 151 , bundle 5A). 
significant than the wire-wrap thermocouples for comparison with SABRE. Points in the rectangular grid of Fig. 22 that lie outside the subchannel flow field are assigned the average temperature of neighboring points within the flow field in Fig. 29.

Several things are readily apparent from inspection of Fig. 29. The outline of the blockage plate is indicated where temperatures rise sharply. The depression in the surface near the middle of the blockage is due to pin No. 16 being inoperative. Finally, SABRE temperatures are higher than experimental data at this axial position, which is near the center of the computed recirculation zone. Increasing FMIX to 2.0 produces a much better fit, as shown in Fig. 30 .

SABRE temperatures and bundle 5A data are compared in Fig. 31 for run $158(40 \%$ flow) with FMIX $=1.0$. Agreement here is quite good. Using

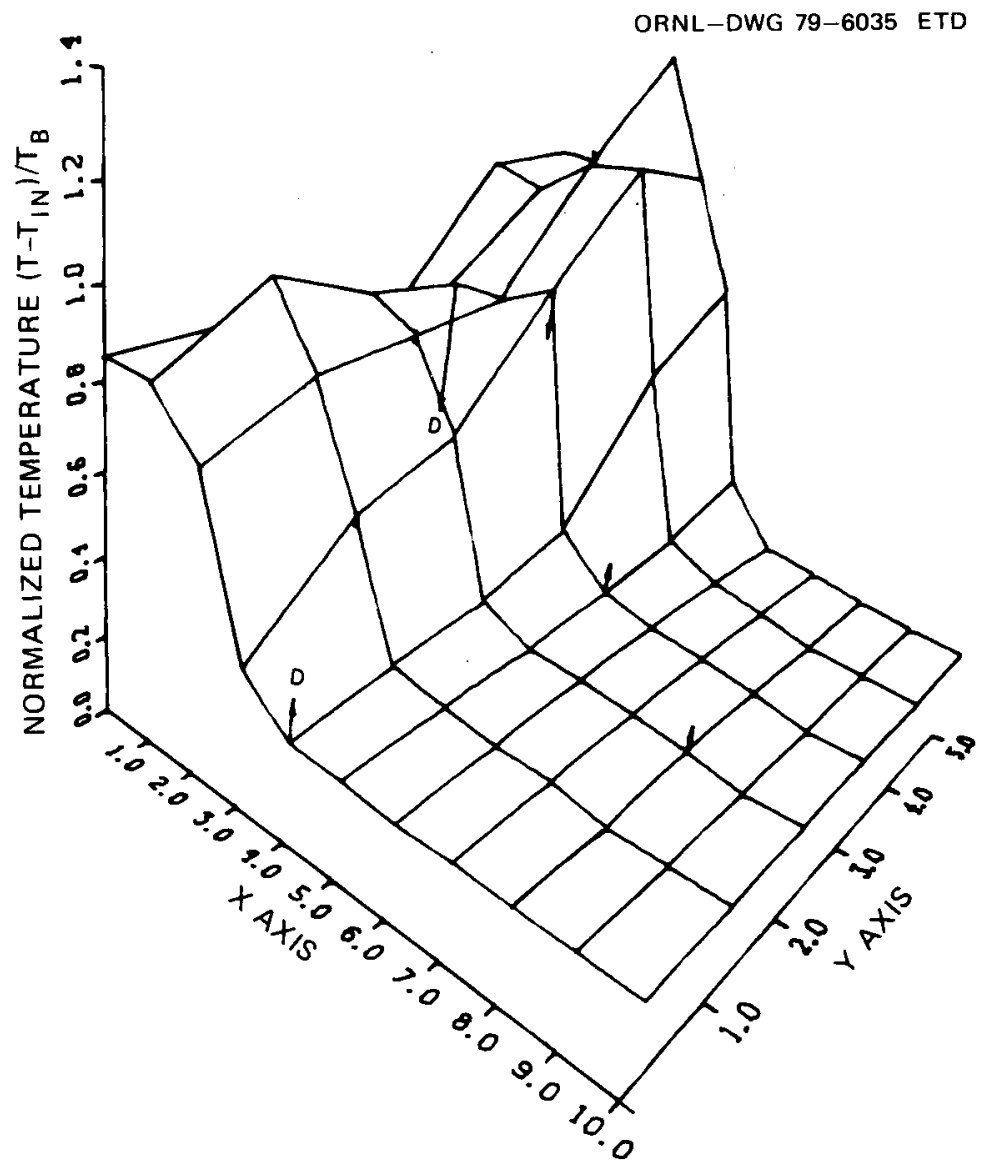

Fig. 30. Comparison of SABRE-1A and experimental data (shown by vectors) at $100 \%$ nominal flow, FMIX $=2.0$ (test 2 , run 151 , bundle $5 \mathrm{~A}$ ). 
ORNL-DWG 79-6036 ETD

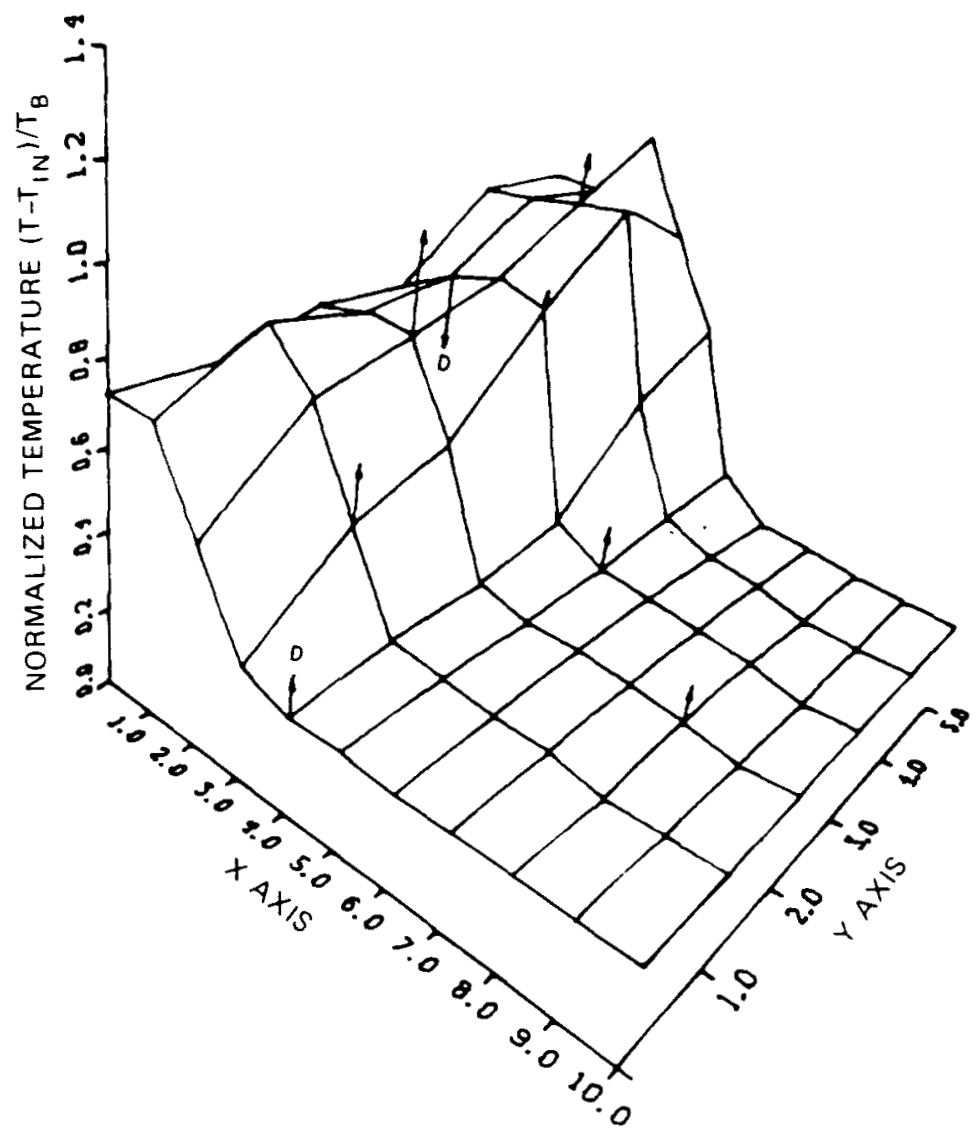

Fig. 31. Comparison of SABRE-IA and experimental data (shown by vectors) at $40 \%$ nominal flow, FMIX $=1.0$ (test 2 , run 158 , bundle $5 \mathrm{~A}$ ).

a value of 1.0 for FMIX at $10 \%$ flow (run 162) gives temperatures much lower than THORS data, as shown in Fig. 32. Reducing FMIX to zero gives better agreement, as shown in Fig. 33. Comparative analysis at this low flow is difficult, however. As the laminar flow regime is approached, the possibilities increase for differences between experimental temperatures measured by wire-wrap internal thermocouples and subchannel average temperatures calculated by SABRE. This can be seen in the discrepancy between SABRE calculations and THORS data in the unblocked subchannel $-(x, y)$ coordinates $(8,2)$ and $(5,3)$ in Fig. 33. However, FMIX must decrease with subchannel Reynolds number in order to give better agreement with THORS data. This, in turn, means that the default mixing correlation in SABRE-lA is not adequate for wire-wrap bundles (which is not surprising). 


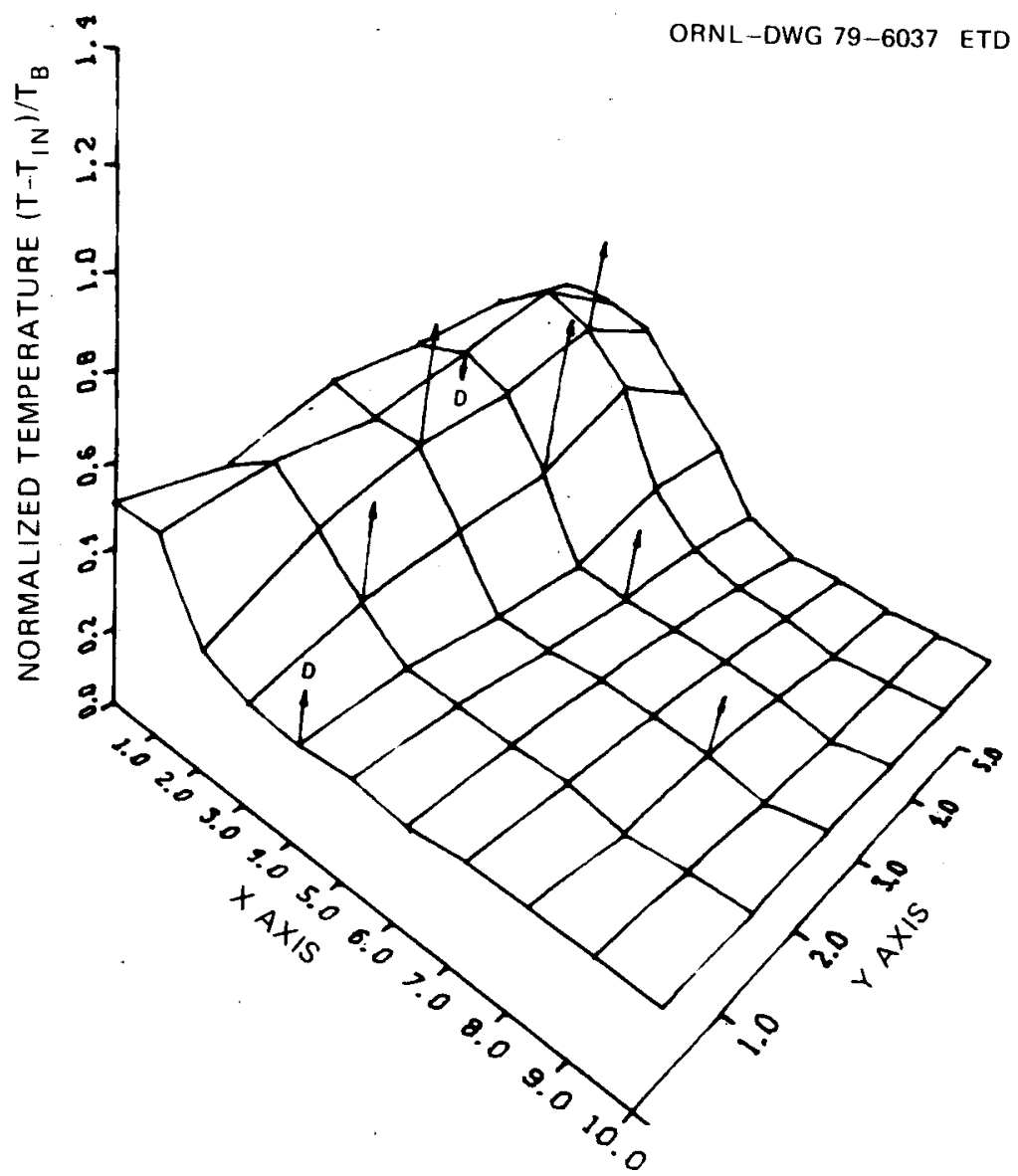

Fig. 32. Comparison of SABRE-1A and experimental data (shown by vectors) at $10 \%$ nominal flow, FMIX $=1.0$ (test 2 , run 162, bundle 5A).

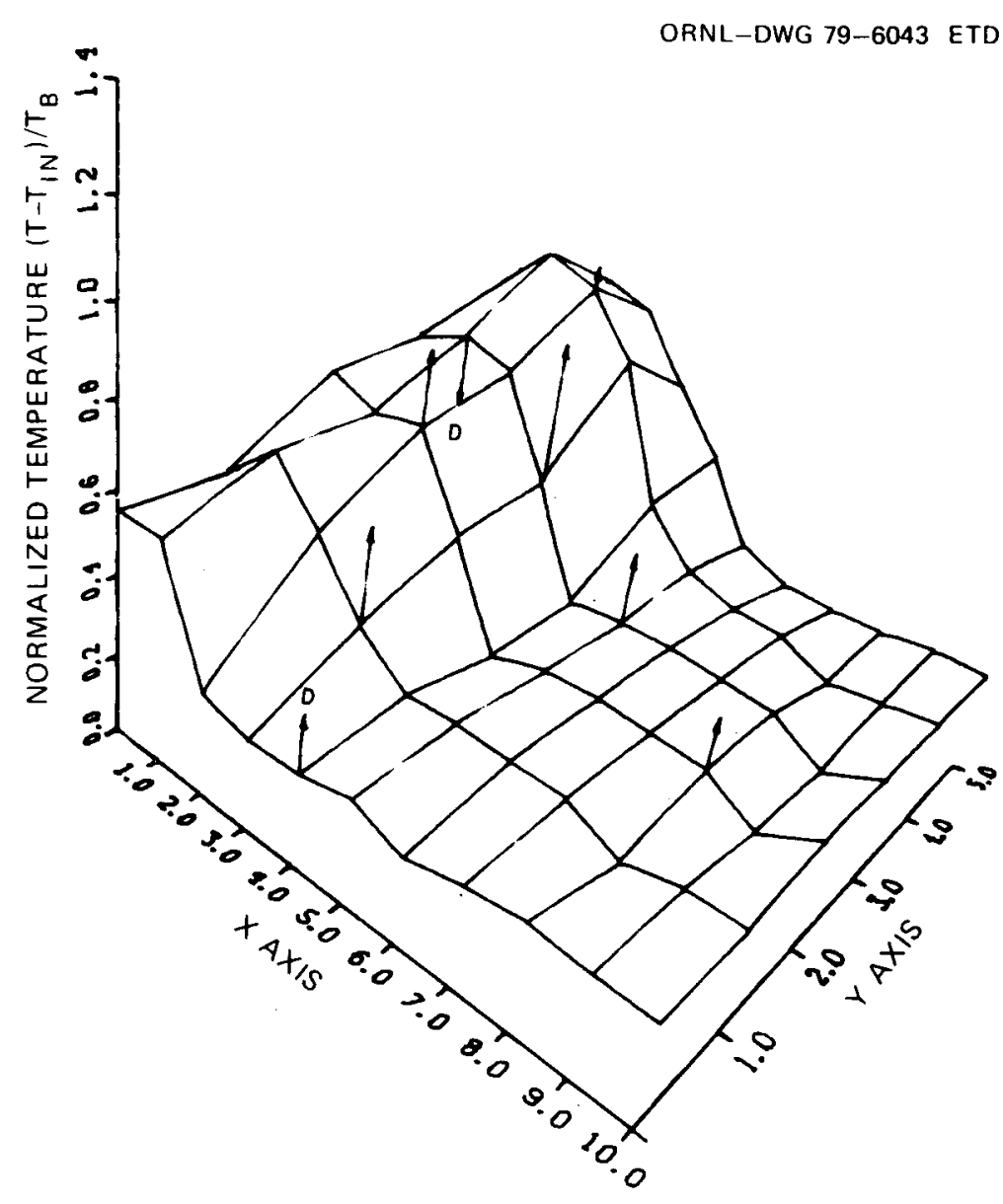

Fig. 33. Comparison of SABRE-1A and experimental data (shown by vectors) at $10 \%$ nominal flow, FMIX $=0.0$ (test 2, run 162, bundle 5A). 
8. SUMMARY AND CONCLUSIONS

SABRE is a fast-running, easy-to-use program with great potential. value for pin bundle blockage analysis. SABRE-1A results for the blocked channels of a six-channel central blockage are in good agreement with wire-wrap and exit-rake thermocouple data in the range of 60 to $100 \%$ of nominal flow using a value of 0.3 for the parameter FMIX. A possible slight decrease of FMIX with inlet flow in this range is indicated. SABRE-1A results can be forced into essential agreement with wire-wrap thermocouple data for the large edge blockage of bundle $5 \mathrm{~A}$ by adjusting FMIX. A value of 2.0 is appropriate at nominal flow, a value of 1.0 at $40 \%$ nominal flow, and best agreement at $10 \%$ nominal flow is with a value of zero for FMIX. The probable reason for the changing value of FMIX is that the SABRE-1A turbulent mixing correlation is not appropriate for wire-wrap bundles. A more appropriate correlation written into a version of SABRE, which includes both the vector upwind differencing method of SABRE-1A and a wire-wrap forced-crossflow model applicable in recirculating flow, would make SABRE a truly valuable tool in wire-wrap bundle blockage analysis. 


\section{REFERENCES}

1. A. D. Gosman et al., The SABRE Code for Prediciton of Coolant Flows and Temperatures in Pin Bundles Containing Blockage, United Kingdom Atomic Energy Authority, Reactor Group (October 1973).

2. R. Potter et al., SABRE-1 - A Computer Program for the Calculation of Three Dimensional Flows in Rod Clusters, United Kingdom Atomic Energy Authority, Reactor Group AEEW-R 1057 (July 1976). "Commercial-in-Confidence."

3. J. N. Lillington, SABRE-1A - A Version of SABRE Incorporating Vector Upstream Differencing, Report FRGN 616 (Apri1 1978).

4. M. H. Fontana et a1., Temperature Distribution in a 19-Rod Simulated LMFBR Fuel Assembly with a Six Channel Internal Blockage (Fuel Failure Mockup Bumdle $3 A$ ) - Record of Experimental Data, Report ORNL/TM5101 (March 1976).

5. M. H. Fontana et al., Temperature Distribution in a 19-Rod Simulated LMFBR Fuel Assembly with an Edge Blockage lout of Reactor Test for ANL FEFP P1 Experiment) - Record of Experimental Data for Fuel Failure Mockup Bundle 5A, Report ORNL/TM-4633 (November 1974).

6. M. H. Fontana and J. L. Wantland, Breeder Reactor Safety and Core Systems Programs Progress Report for October-December 1977, Report ORNL/TM-6288 (June 1978). 
ONRL/TM-6862

Dist. Category UC-79, $-79 e,-79 p$

\section{Internal Distribution}

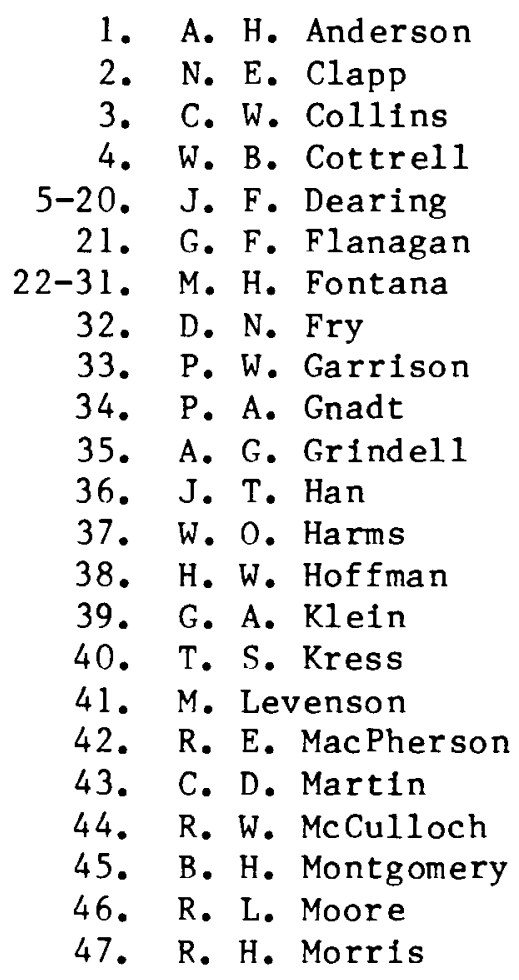

48. F. R. Mynatt

49. W. R. Nelson

50. L. C. Oakes

51. L. F. Parsly

52. P. Patriarca

53. H. Postma

54. R. J. Ribando

55. J. L. Rich

56. W. H. Sides

57. M. J. Skinner

58. I. Spiewak

59. R. S. Stone

60. E. T. Tomlinson

61. H. E. Trammell

62. D. B. Trauger

63. J. L. Wantland

64. G. D. Whitman

65. A. L. Wright

66-67. Central Research Library

68. Y-12 Document Reference Section

69-71. Laboratory Records Department

72. Laboratory Records (RC)

\section{External Distribution}

73. Assistant Administrator, Nuclear Energy, Department of Energy, Washington, DC 20545

74-75. Director, Division of Reactor Development and Demonstration, Department of Energy, Washington, DC 20545

76. Director, Reactor Division, DOE, ORO

77. Office of Assistant Manager for Energy Research and Development, DOE, ORO

78-312. For distribution as shown in TID-4500 under categories UC-79, $-79 e,-79 p$ 